Article

\title{
Three-Dimensional Fibrous Iron as Anode Current Collector for Rechargeable Zinc-Air Batteries
}

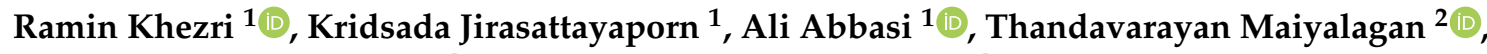 \\ Ahmad Azmin Mohamad ${ }^{3}$ (1) and Soorathep Kheawhom ${ }^{1,4, * *(1)}$ \\ 1 Department of Chemical Engineering, Faculty of Engineering, Chulalongkorn University, \\ Bangkok 10330, Thailand; ramin.k@chula.ac.th (R.K.); 6070111121@student.chula.ac.th (K.J.); \\ ali.a@chula.ac.th (A.A.) \\ 2 Department of Chemistry, SRM Institute of Science and Technology, Kattankulathur, \\ Chennai 603203, Tamilnadu, India; maiyalat@srmist.edu.in \\ 3 School of Materials and Mineral Resources Engineering, Universiti of Sains Malaysia, \\ Nibong Tebal 14300, Malaysia; aam@usm.my \\ 4 Research Unit of Advanced Materials for Energy Storage, Chulalongkorn University, \\ Bangkok 10330, Thailand \\ * Correspondence: soorathep.k@chula.ac.th
}

Received: 17 February 2020; Accepted: 18 March 2020; Published: 19 March 2020

check for updates

\begin{abstract}
A three-dimensional (3D) fibrous structure with a high active surface and conductive pathway proved to be an excellent anode current collector for rechargeable zinc-air batteries (ZABs). Herein, a cost-effective and highly stable zinc (Zn) electrode, based on Zn electrodeposited on iron fibers $(\mathrm{Zn} / \mathrm{IF})$, is duly examined. Electrochemical characteristics of the proposed electrode are seen to compete with a conventional zinc/nickel foam (Zn/NF) electrode, implying that it can be a suitable alternative for use in ZABs. Results show that the $\mathrm{Zn} / \mathrm{IF}$ electrode exhibits an almost similar trend as $\mathrm{Zn} / \mathrm{NF}$ in cyclic voltammetry (CV). Moreover, by using a Zn/IF electrode, electrochemical impedance spectroscopy (EIS) demonstrates lower charge transfer resistance. In the application of a rechargeable $\mathrm{ZAB}$, the fibrous $\mathrm{Zn} / \mathrm{IF}$ electrode exhibits a high coulombic efficiency (CE) of $78 \%$, close to the conventional $\mathrm{Zn} / \mathrm{NF}(80 \%)$, with almost similar capacity and lower charge transfer resistance, after 200 charge/discharge cycles. It is evident that all the positive features of $\mathrm{Zn} / \mathrm{IF}$, especially its low cost, shows that it can be a valuable anode for ZABs.
\end{abstract}

Keywords: zinc-air battery; porous zinc anode; iron fibers; electrochemical performances

\section{Introduction}

A cost-effective, reliable and affordable electrical energy storage system (EESS) with low environmental impact is necessary for renewable energy generation and conversion [1]. In both supply and demand, EESS plays a vital role in enhancing the stability and flexibility of a power grid [2,3]. The most common kind of EESS is a rechargeable battery. Lithium-ion batteries (LIBs) are widely recognized as the most viable solution due to their excellent performance and flexible applications. Nevertheless, LIBs exhibit numerous deficiencies, such as high cost and safety issues [4-6]. Specifically, there are concerns regarding raw material supply $[7,8]$.

Unlike lithium ( $\mathrm{Li}), \mathrm{Zn}$ is more cost-effective $(\sim \$ 0.9 / \mathrm{lb})$ and globally abundant $(\sim 300$ times higher than $\mathrm{Li}$ in the earth's crust) $[9,10]$. A Zn anode offers greater safety and a higher specific volumetric capacity $\left(5855 \mathrm{mAh} / \mathrm{cm}^{3}\right)$ compared to that of $\mathrm{Li}\left(2066 \mathrm{mAh} / \mathrm{cm}^{3}\right)$ [11,12]. Furthermore, $\mathrm{Zn}$ is primarily used in industry and can be easily recycled using existing technologies [13]. $\mathrm{Zn}$ is also considered a significant contributor to the circular economy. 
Zinc-air batteries (ZABs) are particularly attractive as a sustainable and inexpensive solution for large-scale EESS, owing to their low cost, eco-friendliness, safety, long-term durability and very high energy density $(1.35 \mathrm{kWh} / \mathrm{kg})[14,15]$. Primary ZABs have been most successfully implemented in medical and telecommunication applications, such as hearing aids, navigation lights and railway signals. ZABs consist of three major parts: a $\mathrm{Zn}$ anode, an electrolyte and an air cathode. In the preparation of air cathodes, catalytic layers are usually used either in single layer or multiple layer. This is carried out in order to enhance the slow kinetics of the oxygen reduction reaction (ORR) and to improve the cycle life of the ZABs. Some instances of commonly used catalysts in ZAB cathodes are silver $[14,15]$ and manganese dioxide $\left(\mathrm{MnO}_{2}\right)$. Furthermore, in ZABs, the electrolyte plays a crucial role as a medium for ionic migration during discharge/charge. Aqueous alkaline solutions, such as the potassium hydroxide $(\mathrm{KOH})$ solution, have high ionic conductivity and relatively high influence on ORR; therefore, they are considered suitable for use in ZABs. Furthermore, inorganic additives, salts and organic solvents are sometimes added to the $\mathrm{KOH}$ electrolyte to suppress the problems of dendrite growth and $\mathrm{Zn}$ corrosion as the result of the hydrogen evolution reaction (HER) in ZABs. A unique feature of $Z A B s$ is that only the active anode material $(\mathrm{Zn})$ is stored inside the battery system. In contrast, the active cathode material (oxygen) is drawn directly from the ambient air. Considering all positive features of ZABs, there are some challenges that have to be taken into account, such as dendrite growth, shape change as well as passivation of the $\mathrm{Zn}$ anode upon cycling [16]. The adoption of a proper anode structure can overcome these common challenges and can enhance the performance of ZABs [17].

The aforementioned issues can be solved by adopting a three-dimensional (3D) porous structure of the $\mathrm{Zn}$ anode [18]. Thereby, the current is uniformly distributed throughout the electrode, while the void structure constrains the dissolution/precipitation processes. Typically, in ZABs, the use of porous anodes is advantageous in presenting a large active surface for the deposition of $\mathrm{Zn}$ ions, indicating a great specific capacity for energy storage purposes [19]. Traditionally, nickel foam (NF) has been widely used as the anode current collector as it offers a large active surface and a continuous conductive porous 3D network. NF, despite its high porosity and surface area, has good electrical conductivity, high corrosion resistance and superior mechanical properties, and also has been found to be an excellent electrocatalyst for HER [20,21]. The usage of nickel is linked to economic development; the world's demand for nickel has increased at an annual rate of $3.8 \%$ since 2000. Furthermore, nickel is only mined in a small selection of countries, e.g., Indonesia, Philippines and Russia, which creates a potential supply risk [22]. Thus, the development of alternative, inexpensive earth-abundant electrode materials with improved or comparable electrochemical properties to NF and a high active surface is of great significance. A higher surface area of anode material offers several benefits. It provides smaller local current densities and suppresses the potential of passivation of the $\mathrm{Zn}$ anode. Likewise, it reduces the featured dendrite growth [23]. Iron fibers (IF) are highly porous renewable materials which are cheap and have high conductivity due to mechanical integrity and connectivity of the fibrous structure. Therefore, they are considered a promising candidate for this purpose [24].

Synthesis and application of porous anode material have continuously been a focal point among many researchers [25]. Previously, performance of a $\mathrm{Zn}$ anode was enhanced using fibrous materials for a high power application of ZABs; large capacity at a high discharging current was reported [26]. In order to inhibit the passivation of the $\mathrm{Zn}$ anode induced by pore plugging, a pasted $\mathrm{Zn}$ electrode was prepared from an aqueous slurry containing Zn oxide (ZnO), polytetrafluoroethylene (PTFE), lead oxide $(\mathrm{PbO})$ (to suppress hydrogen evolution) and cellulose. According to the results, both cycle life and peak power drain capability were improved by the addition $10 \mathrm{wt} . \%$ cellulose to the pasted $\mathrm{Zn}$ electrode [27]. Moreover, a porous Zn anode made from Zn powder, rather than a planar Zn plate, was demonstrated. The impact of a higher effective surface area on anode mass utilization and capability of the rechargeable alkaline battery was investigated. As a result, a larger discharge capacity was observed for the porous $\mathrm{Zn}$ electrode than that of the planar Zn plate [28]. 
This work presents a low-cost alternative to the conventional NF to support the anode material. The main aim is to further reduce the cost of ZABs. Hence, a 3D fibrous material as anode current collector was synthesized from IF. Initially, it was intended to create a consistent IF platform to support $\mathrm{Zn}$ on the anode current collector effectively. Then, the prepared IF-based anode electrode underwent a series of analyses to determine its electrochemical properties. Furthermore, the synthesized $\mathrm{Zn} / \mathrm{IF}$ anode was implemented and examined in a ZAB. Consequently, the performance of the featured electrode was investigated and compared with a conventional $\mathrm{Zn} / \mathrm{NF}$ electrode.

\section{Materials and Methods}

\subsection{Chemicals and Materials}

An NF sheet of $99.97 \%$ purity, 100 pores per inch and $1 \mathrm{~mm}$ thickness (Qijing Trading Co., Ltd., Jiangxi, China) was used as current collector for the anode (in fabrication of benchmark electrode) and cathode (in ZAB). An IF of 99\% purity, $20 \mu \mathrm{m}$ thickness and $1.8 \mathrm{~nm}$ pore size (Ezhou Baofeng Metal Wool Technology Co., Ltd., Hubei, China) were used as the anode current collector and working electrode for Cyclic Voltammetry (CV) analysis. Zn foil of 99.9\% purity, (Shandong AME Energy Co., Ltd., Shenzhen, China) and Zn (Sigma-Aldrich, USA) were used in the electroplating process. A copper sheet of $150 \mu \mathrm{m}$ thickness (Yueqing Kangsheng Copper Co., Ltd., Zhejiang, China) was used as anode current collector (for $\mathrm{Zn} / \mathrm{IF}$ electrode). Potassium hydroxide $(\mathrm{KOH})$ pellets of $99 \%$ purity (Elago Enterprises Pty. Ltd., Sydney, Australia) and zinc oxide $(\mathrm{ZnO})$ grade AR (Elago Enterprises Pty. Ltd., Sydney, Australia) were used in the synthesis of the electrolyte. Manganese (IV) oxide $\left(\mathrm{MnO}_{2}\right)$, $5 \mu \mathrm{m}, 99.99 \%$ purity (Sigma-Aldrich, USA), with carbon blacks (XC 72R), (Cabot Corporation, United States) and carbon blacks (BP2000) (Cabot Corporation, United States) were used in the preparation of the cathode electrode. Finally, polyvinylidene fluoride (PVDF), (Sigma-Aldrich, USA), graphite (Timcal KS6), (Sigma-Aldrich, USA) and dimethyl fumarate (DMF), (Sigma-Aldrich, USA) were used in the preparation of the binder.

\subsection{Electrode and Battery Fabrication}

As shown in Figure 1, a ZAB was assembled and used to evaluate polarization and galvanostatic discharge characteristics. The battery consisted of a $\mathrm{Zn} / \mathrm{IF}$ electrode as an anode, a porous air cathode electrode, a cylindrical cell casing and a solution electrolyte. To fabricate the anode electrode, copper sheets were cut in pieces of $5 \times 1 \mathrm{~cm}^{2}$ in dimension. Then, the sheets were smoothed with sandpaper (No. 4) and washed with acetone. Initially, the IF were washed with acetone and heated in an incubator for $4 \mathrm{~h}$ at $\mathrm{T}=60^{\circ} \mathrm{C}$. Next, the IF were cut to cover an area of copper $\left(1 \times 1 \mathrm{~cm}^{2}\right)$ at a density of $40 \mathrm{mg} / \mathrm{cm}^{2}$. The IF were adhered to a copper sheet using a binder comprised of a graphite and PVDF mixture with a ratio of 85:15 (wt./wt.) dissolved in $5 \mathrm{~mL}$ dimethyl fumarate (DMF) solvent. As illustrated in Figure 2, the surface of the copper was intended to be fully covered by the IF to avoid the contact of copper with the electrolyte solution. The electrode was placed into a vacuum cabinet at $\mathrm{T}=60^{\circ} \mathrm{C}$. Finally, in preparation of the anode, a $\mathrm{Zn}$ was electroplated on the IF electrode using a $\mathrm{Zn}$ sulfate solution $(1 \mathrm{M})$ under a current density of $20 \mathrm{~mA} / \mathrm{cm}^{2}$, for a duration of $1 \mathrm{~h}$.

The porous air cathode consisted of three layers: a gas diffusion layer, a current collector and a catalyst layer. The $\mathrm{MnO}_{2}$-based catalyst layer, which is directed to be in contact with the electrolyte, was synthesized via mixing powdered carbon (BP2000) and $\mathrm{MnO}_{2}$ in a ratio of 70:30 (wt./wt.). Polystyrene was added as binder along with toluene $5 \%$. Then, this mixture was applied to the inner surface of the $\mathrm{NF}$ (current collector) via brushing and inserted into a hot press for $10 \mathrm{~min}$ at $\mathrm{T}=150{ }^{\circ} \mathrm{C}$ [29]. The air side (gas diffusion layer) consisted of combined carbon (XC 72R) and polytetrafluoroethylene in a ratio of 40:60 (wt./wt.). Next, $35 \mathrm{~mL}$ ethanol was added as solvent, applied onto the outer side of the NF and hot pressed at $\mathrm{T}=350{ }^{\circ} \mathrm{C}$ for $15 \mathrm{~min}$. Furthermore, an aqueous solution containing $6 \mathrm{M}(\mathrm{KOH})$ and $0.24 \mathrm{M}(\mathrm{ZnO})$ having a total volume of $20 \mathrm{~mL}$ was used as electrolyte solution. 


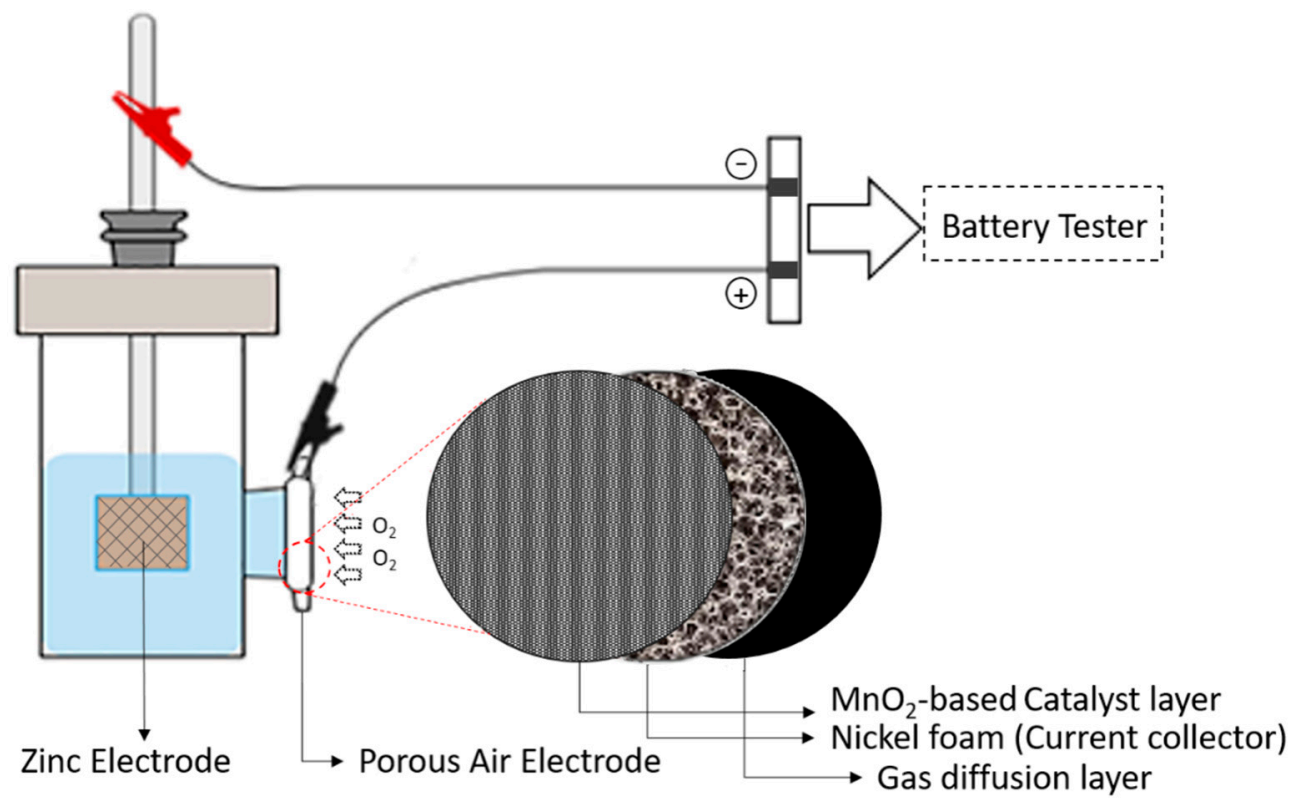

Figure 1. Schematic demonstration of the zinc-air battery (ZAB).

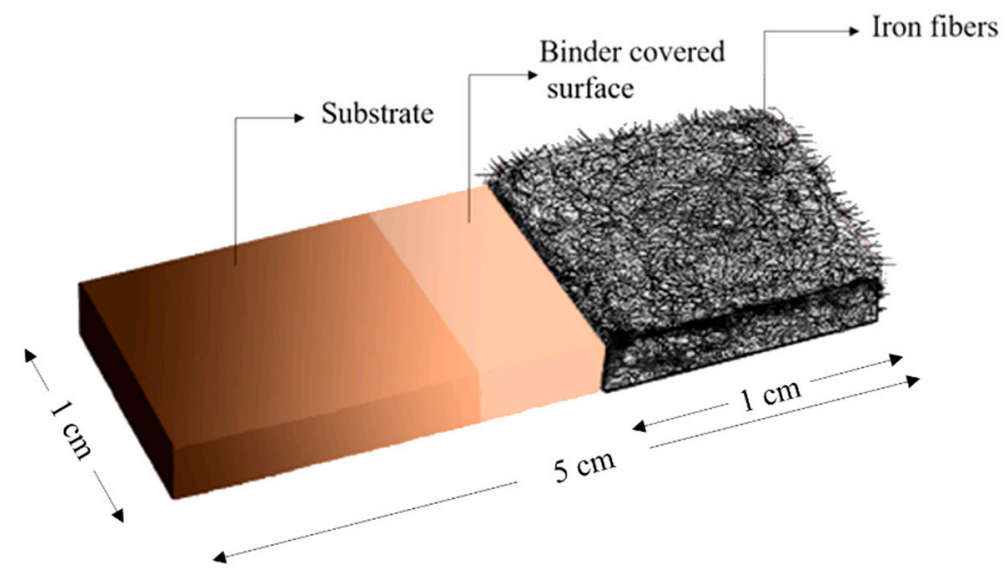

Figure 2. The anode electrode consisted of iron fibers (IF) adhered to the copper sheet.

\subsection{Characterization and Measurement}

For the purpose of electrochemical characterization, an electrochemical cell, having three electrodes, was employed accordingly. Electrochemical characterization techniques involved the following: CV, electrochemical impedance spectroscopy (EIS), potentiodynamic polarization (Tafel experiment) and chronoamperometry. Further, morphology of the $\mathrm{Zn}$ deposition, on both anodes, was studied via scanning electron microscopy (SEM), using a field emission SEM (ZEISS Sigma 500, Carl Zeiss AG, Oberkochen, Germany), at an accelerating voltage between $5 \mathrm{kV}$ at a working distance between 1 and $5 \mathrm{~mm}$. Energy dispersive X-ray (EDX) spectroscopy (SmartEDX, Carl Zeiss AG, Oberkochen, Germany) by a $30 \mathrm{~mm}^{2}$ detector using holey carbon grids was undertaken for elemental mapping. The Brunauer-Emmett-Teller (BET) analysis was conducted via the 3Flex physisorption setup (ASAP2010, Micromeritics Instrument Corp, Ottawa, Ontario, Canada) using nitrogen at $77 \mathrm{~K}$ to determine the surface area of the samples. The samples were outgassed via the use of nitrogen at $150{ }^{\circ} \mathrm{C}$ for $16 \mathrm{~h}$ before measurements. For all electrochemical characterizations, a $\mathrm{Zn}$ anode was used as working electrode, a platinum plate as counter electrode and mercury/mercury oxide $(\mathrm{Hg} / \mathrm{HgO})$ as reference electrode; except for multicycle $\mathrm{CV}$ where the working and counter electrodes were used in reverse order. Electrochemical techniques were carried out via a potentiostat/galvanostat with 
an impedance measurement unit (PAR VersaSTAT 3A, AMETEK Inc., Berwyn, Pennsylvania, USA), and the data were obtained and analyzed using VersaStudio software (2.60.6, AMETEK Inc., Berwyn, Pennsylvania, USA). CV was performed in the range of -1.6 to $-0.7 \mathrm{~V}$ vs. $\mathrm{Hg} / \mathrm{HgO}$ at a scan rate of $7 \mathrm{mV} / \mathrm{s}$. For potentiodynamic polarization, the measurements were carried out as follows: anode materials were immersed for $30 \mathrm{~min}$ in solution electrolyte, at room temperature, within the voltage range of -0.5 to $+0.5 \mathrm{~V}$ vs. open-circuit voltage $(\mathrm{OCV})$ at a scan rate of $1.67 \mathrm{mV} / \mathrm{s}$. EIS was applied at a frequency range of $100 \mathrm{kHz}$ to $0.1 \mathrm{~Hz}$ at $10 \mathrm{mV}$ of amplitude. Thus, the obtained EIS spectra were analyzed via Zsimpwin software (3.60, AMETEK Inc., Berwyn, Pennsylvania, USA). The influence of $\mathrm{Zn}$-deposition by an applied potential was investigated via chronoamperometry in a range of -1.45 to $-1.60 \mathrm{~V}$ vs. $\mathrm{Hg} / \mathrm{HgO}$. Furthermore, the electrostatic charge/discharge performance of the Zn electrodes was evaluated for cyclic stability and cycle lifespan, using a ZAB wherein the cell was charging with a constant current of $10 \mathrm{~mA}$ for $160 \mathrm{~s}$ followed by resting for $60 \mathrm{~s}$, and then discharging under a constant current density of $10 \mathrm{~mA} / \mathrm{cm}^{2}$ to a cut-off voltage of $0.8 \mathrm{~V}$. Polarization characteristics of the ZAB were evaluated by a battery testing system (NEWARE, CT-4008-5V20mA, Neware Technology Ltd., Shenzhen, China). The data were collected and analyzed via battery tester software (BTS 7.6.0, Neware Technology Ltd., Shenzhen, China).

\section{Results and Discussion}

\subsection{Electrochemical Characterization}

CV was performed on three substrates: a pure copper sheet, a copper plate having IF adhered to IF/Cu and NF. This was carried out in order to examine whether the substrates, to some extent, were involved with the redox chemistry that occurred at the electrode/electrolyte interface. As shown in Figure 3, CV was performed at a scan rate of $7 \mathrm{mV} / \mathrm{s}$ within a potential range of -1.7 to $0.5 \mathrm{~V}$ vs. $\mathrm{Hg} / \mathrm{HgO}$.

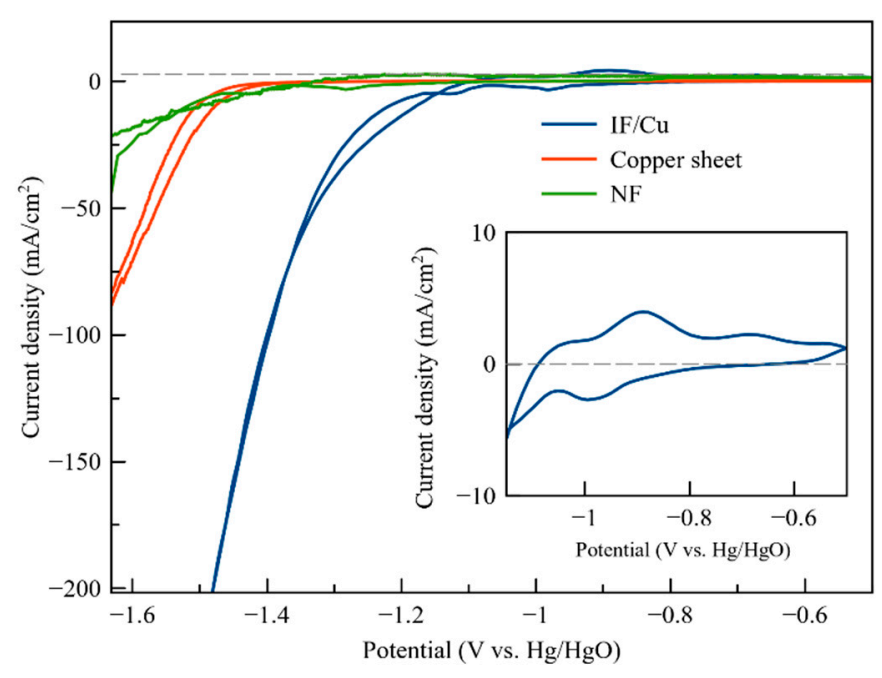

Figure 3. Cyclic voltammetry $(\mathrm{CV})$ of copper sheet, $\mathrm{IF} / \mathrm{Cu}$ and $\mathrm{NF}$ substrates at a scan rate of $7 \mathrm{mV} / \mathrm{s}$ within a potential range of -1.7 to $0.5 \mathrm{~V}$ vs. $\mathrm{Hg} / \mathrm{HgO}$.

For copper and NF substrates, the voltammograms exhibited a smooth-lined shape with no substantial peaks, indicating the lack of any oxidation/reduction reactions. However, some small peaks were observed between the potentials of -0.889 and $-0.683 \mathrm{~V}$ vs. $\mathrm{Hg} / \mathrm{HgO}$ in the voltammogram of the IF/Cu substrate. The magnitude of the peaks is relatively small $\left(< \pm 5 \mathrm{~mA} / \mathrm{cm}^{2}\right)$ and would most probably be eliminated when the IF surface has been fully coated by the Zn particles. The peaks were 
in accordance with slight oxidation of iron into $\mathrm{Fe}^{2+}$ and $\mathrm{Fe}^{3+}$ ions while reacting with the hydroxide ions from the electrolyte, according to Equations (1)-(3) [30]:

$$
\begin{gathered}
\mathrm{Fe}+2 \mathrm{OH}^{-} \rightleftharpoons \mathrm{Fe}(\mathrm{OH})_{2}+2 \mathrm{e}^{-} \\
\mathrm{Fe}(\mathrm{OH})_{2}+\mathrm{OH}^{-} \rightleftharpoons \mathrm{FeOOH}+\mathrm{H}_{2} \mathrm{O}+\mathrm{e}^{-} \quad \mathrm{E}^{0}=-0.56 \mathrm{~V} \\
3 \mathrm{Fe}(\mathrm{OH})_{2}+2 \mathrm{OH}^{-} \rightleftharpoons \mathrm{Fe}_{3} \mathrm{O}_{4}+4 \mathrm{H}_{2} \mathrm{O}+2 \mathrm{e}^{-} \quad \mathrm{E}^{0}=-0.66 \mathrm{~V}
\end{gathered}
$$

Due to the high active area/porosity introduced by the IF, when the Zn/IF electrode is in contact with an electrolyte, a higher number of metal ions can be dissolved from the anode surface into the solution medium and become involved in zincate formation reactions, according to Equation (4) and Equation (5). Thus, higher activity is expected to be attained in the presence of a porous anode.

$$
\begin{aligned}
& \mathrm{Zn}+4 \mathrm{OH}^{-} \rightleftharpoons \mathrm{Zn}(\mathrm{OH})_{4}^{2-}+2 \mathrm{e}^{-} \\
& \mathrm{Zn}+3 \mathrm{OH}^{-} \rightleftharpoons \mathrm{Zn}(\mathrm{OH})_{3}^{-}+2 \mathrm{e}^{-}
\end{aligned}
$$

To evaluate this, CV was adopted to investigate the electrochemical properties of the $\mathrm{Zn} / \mathrm{IF}$ and $\mathrm{Zn} / \mathrm{NF}$ anodes. Current density values were recorded when different potentials were applied to the system in the forward/reverse scan. In Figure $4 a$, the results of CV are shown. The voltammograms are almost similar for both anodes. However, there was not much difference in anodic/cathodic peaks, suggesting that an almost similar mechanism of $\mathrm{Zn}$ dissolution/deposition occurred in both electrodes. However, around the potentials of -1.15 to $-1 \mathrm{~V}$ vs $\mathrm{Hg} / \mathrm{HgO}$ a slightly larger magnitude of current density at the anodic peak was observed for the $\mathrm{Zn} / \mathrm{IF}\left(351 \mathrm{~mA} / \mathrm{cm}^{2}\right)$ rather than that of $\mathrm{Zn} / \mathrm{NF}$ $\left(347 \mathrm{~mA} / \mathrm{cm}^{2}\right)$. Although the difference was not significant, the higher current density suggested that enhanced kinetics of oxidation and formation of zincate ions occurred in the forward scan, due to the presence of an electron transport channel throughout the porous region [31]. Moreover, a second anodic peak was observed for both electrodes in a reverse scan around the similar potential of the anodic peak. The formation of $\mathrm{ZnO}$, on the forward scan, was followed by its precipitation on the electrode surface, thus forming a passive layer which reduced the active area of the electrode. However, the $\mathrm{Zn}$ ions which did not oxidize in the forward scan tended to oxidize in the reverse scan, due to the breakdown of the passive layer at the very oxidation potential range [32]. The Zn/IF electrode exhibited a smaller oxidation peak in reverse scan that slightly shifted to negative potentials, suggesting that the passivation film was more stable and less soluble in the presence of the fibrous iron electrode. As for the $\mathrm{CV}$ results, both electrodes exhibited the crossover between the anodic and cathodic traces at the potentials of 0.148 and $0.214 \mathrm{~V}$ vs. $\mathrm{Hg} / \mathrm{HgO}$ - related to $\mathrm{Zn} / \mathrm{NF}$ and $\mathrm{Zn} / \mathrm{IF}$, respectively. The crossover occurred due to the difference in deposition and dissolution onset potentials corresponding to nuclei formation on the electrode.

Figure $4 \mathrm{~b}$ shows Nyquist diagrams of the $\mathrm{Zn} / \mathrm{IF}$ and $\mathrm{Zn} / \mathrm{NF}$ electrodes, at a frequency range from $100 \mathrm{kHz}$ to $0.1 \mathrm{~Hz}$ with alternate current amplitude of $10 \mathrm{mV}$ around OCV. In Supplementary Materials (Figure S1a,b), Bode diagrams are presented. In both cases, the spectrums have quite similar shapes, indicating the equivalent mechanism of $\mathrm{Zn}$ dissolution. Further, according to Figure $4 \mathrm{~b}$, the semicircles pertain to the charge-transfer resistance $\left(R_{\mathrm{ct}}\right)$, demonstrating the occurrence of charge transfer at the electrode/electrolyte interface. According to the EIS diagrams, Zn/IF exhibited a smaller semicircle at high frequency, thus denoting a lower charge transfer resistance and faster surface reactions than $\mathrm{Zn} / \mathrm{NF}$, which is considered an advantage in the charge/discharge processes. The smaller $\mathrm{R}_{\mathrm{ct}}$ can be ascribed to the higher rate of anodic reactions and $\mathrm{Zn}$ dissolution indicated by the $\mathrm{Zn} / \mathrm{IF}$ electrode [33]. An efficient electron transport for oxidation reaction is also attributed by the small charge transfer resistance. Moreover, no Warburg impedance was observed at a low frequency. Warburg impedance is associated with diffusion of soluble $\mathrm{Zn}$ ions from the electrode surface into the bulk electrolyte and is usually identified by a small inclined line at low frequencies [34,35]. EIS data including the $R_{c t}$ 
and solution resistance $\left(R_{s}\right)$ were calculated from the equivalent circuit model to fit with the Nyquist plots. In Table 1, the results are shown. $Q$ is a constant phase element describing the capacitance of the electrode/solution interface. $R_{S}$ denotes the resistance between the reference and working electrodes, which depends on the type of ions, ionic concentration, ion conductivity, temperature, and other physicochemical characteristics of the solution electrolyte employed. In the EIS analysis, a similar electrolyte was used for both electrodes; thus, the $R_{s}$ values were found to be close. Moreover, results confirmed the smaller charge transfer resistance of the $\mathrm{Zn} / \mathrm{IF}$ electrode $(4.877 \Omega)$, which was about 0.47 percent lower than that of $\mathrm{Zn} / \mathrm{NF}(9.215 \Omega)$. Typically, the high electroactive area introduced by porous electrodes accommodates the strain induced by the volume variations during the deposition of $\mathrm{Zn}$ ions and therefore are capable of reducing the deterioration of the electrode surface, as compared to less porous types [36].

a)
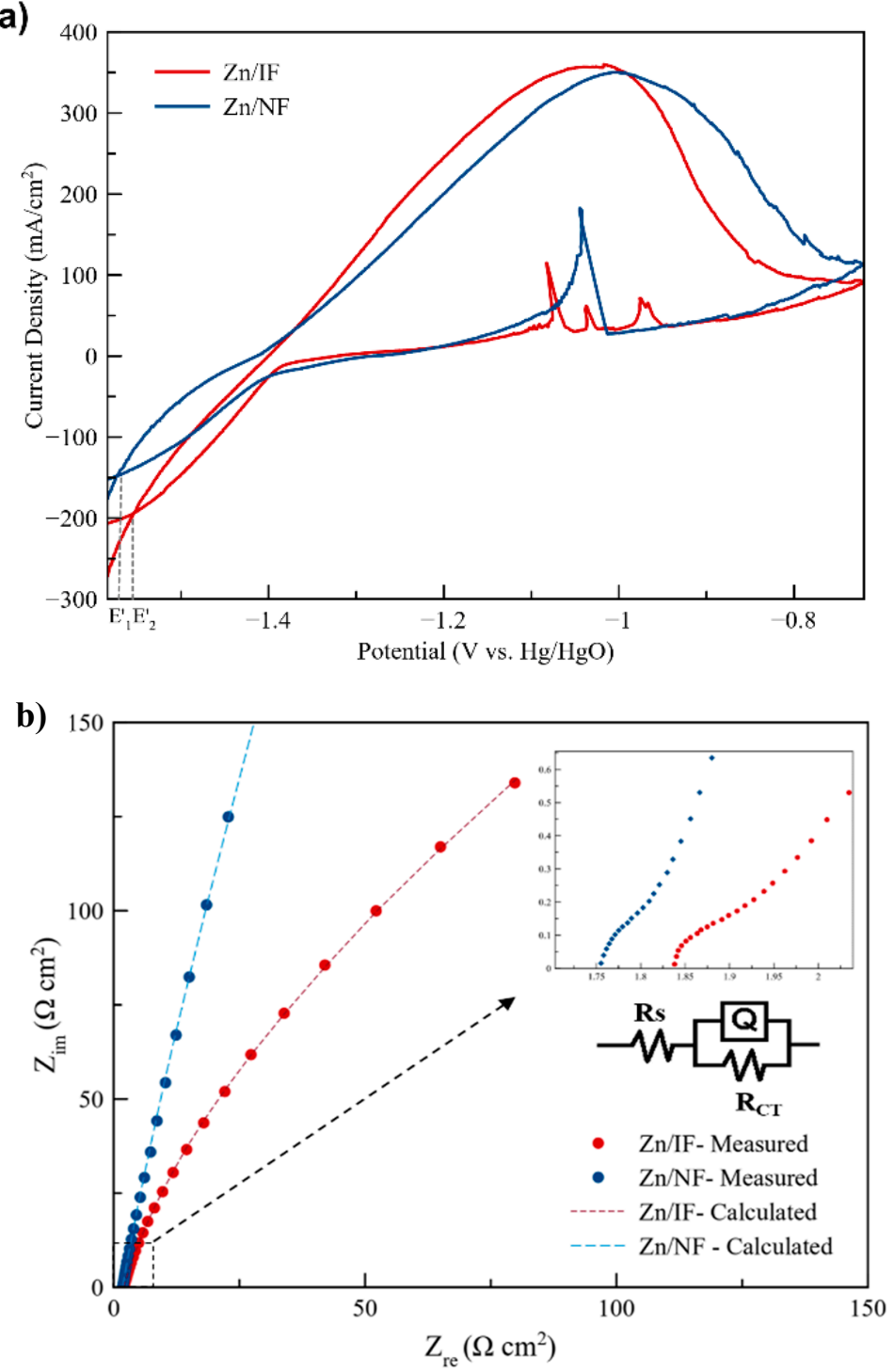

Figure 4. (a) $\mathrm{CV}$ at a scan rate of $7 \mathrm{mV} / \mathrm{s}$ within a potential range of -1.70 to $-0.7 \mathrm{mV}$ vs. $\mathrm{Hg} / \mathrm{HgO}$ and (b) Nyquist plots with fitted lines and equivalent circuit model at a starting frequency of $100 \mathrm{kHz}$ to 0.1 $\mathrm{Hz}$ for $\mathrm{Zn} / \mathrm{IF}$ and $\mathrm{Zn} / \mathrm{NF}$ around open-circuit voltage (OCV). 
Table 1. Resistance values of $\mathrm{Zn}$ anodes in the solution electrolyte.

\begin{tabular}{ccccc}
\hline \multirow{2}{*}{ Anode } & \multirow{2}{*}{$\mathbf{R}_{\mathbf{S}}(\boldsymbol{\Omega})$} & $\mathbf{R}_{\mathrm{CT}}(\boldsymbol{\Omega})$ & \multicolumn{2}{c}{$\mathbf{Q}, \mathrm{CPE}\left(\mathrm{S} / \mathbf{s}^{\wedge} \mathbf{n}\right)$} \\
\cline { 4 - 5 } & & & $\mathbf{Y}_{\mathbf{0}}\left(\mathbf{s}^{\mathbf{n}} / \mathbf{\Omega} \times \mathbf{1 0}^{\mathbf{6}}\right)$ & $\mathbf{0}<\mathbf{n}<\mathbf{1}$ \\
\hline $\mathrm{Zn} / \mathrm{IF}$ & 1.832 & 4.877 & $1.143 \times 10^{-3}$ & 0.845 \\
$\mathrm{Zn} / \mathrm{NF}$ & 1.761 & 9.215 & $5.329 \times 10^{-4}$ & 0.905 \\
\hline
\end{tabular}

The 3D structure of the anode surface corresponds with an altered corrosion inhibition property of the electrode. It is also crucial to determine the corrosion behavior of an electrode through understanding the kinetics of dissolution and hydrogen evaluation, as it significantly affects the performance and shelf-life of the batteries. Therefore, the potentiodynamic polarization analysis of the electrodes was carried out at a scan rate of $1.67 \mathrm{mV} / \mathrm{s}$ within the potential range of -0.5 to $+0.5 \mathrm{~V}$ vs. OCV. In Figure 4, the results of the Tafel polarization analysis are indicated. In Table 2, the corrosion potential $\left(\mathrm{E}_{\mathrm{corr}}\right)$ and corrosion current density $\left(\mathrm{I}_{\mathrm{corr}}\right)$ and other parameters are listed.

Table 2. Corrosion parameters of metals in solution electrolyte.

\begin{tabular}{ccccccc}
\hline Anode & $\begin{array}{c}\mathrm{E}_{\text {corr }} \\
\mathbf{( V ~ v s . ~} \mathbf{H g} / \mathbf{H g O})\end{array}$ & $\begin{array}{c}\mathbf{I}_{\text {corr }} \\
\left(\mathbf{m A} / \mathbf{c m}^{\mathbf{2}}\right)\end{array}$ & $\begin{array}{c}\boldsymbol{\alpha}_{\mathbf{a}} \\
(\mathbf{m V} / \mathbf{d e c a d e})\end{array}$ & $\begin{array}{c}-\boldsymbol{\alpha}_{\mathbf{c}} \\
(\mathbf{m V} / \text { decade })\end{array}$ & $\mathbf{R}_{\mathbf{p}}(\boldsymbol{\Omega})$ & $\mathbf{C R}$ \\
\hline Zinc Plate & -1.427 & 3.430 & 0.069 & 0.252 & 0.690 & 6.245 \\
Zn/NF & -1.577 & 5.091 & 0.086 & 0.733 & 0.656 & 7.430 \\
Zn/IF & -1.291 & 5.912 & 0.077 & 0.182 & 0.397 & 9.761 \\
\hline
\end{tabular}

Following the Butler-Volmer equation (compact form) for the anodic and cathodic reactions, the Tafel equation can be described, as shown in Equation (6):

$$
\mathrm{E}-\mathrm{E}_{\mathrm{corr}}=\frac{2.3 \mathrm{RT}}{\alpha \mathrm{F}} \log (\mathrm{i})-\frac{2.3 \mathrm{RT}}{\alpha \mathrm{F}} \log \left(\mathrm{i}_{0}\right)
$$

where $\mathrm{I}$ and $\mathrm{I}_{\text {corr }}$ are the measured and corrosion current densities, respectively; $\mathrm{E}$ and $\mathrm{E}_{\mathrm{corr}}$ are the electrode and corrosion potentials, respectively; and $\alpha$ is the symmetry factor. Tafel curves can be considered straight lines at potentials close to $\mathrm{E}_{\text {corr }}$. The value of $\mathrm{I}_{\text {corr }}$ can be determined by the extrapolation of the cathodic Tafel curve to the $\mathrm{E}_{\text {corr }}$. The slope of each Tafel curve represents the corresponding polarization resistance $\left(R_{p}\right)$, which denotes the transition resistance between the electrodes and the electrolyte and is derived according to the well-known Stern-Geary equation [37], as shown in Equation (7):

$$
\mathrm{R}_{\mathrm{p}}=\frac{\alpha_{\mathrm{a}}\left|\alpha_{\mathrm{c}}\right|}{2.303 \mathrm{I}_{\mathrm{corr}}\left(\alpha_{\mathrm{a}}+\left|\alpha_{\mathrm{c}}\right|\right)}
$$

where $\alpha_{a}$ and $\alpha_{c}$ are the slopes of Tafel curves related to the anodic and cathodic branches of partial reactions, respectively. The corrosion rate (CR) generally corresponds to the corrosion current density along with the surface area of the working electrode $(\mathrm{Zn})$ and alters due to porosity and accumulation of corrosion products [38]. CR can be determined by applying the parameters calculated, as in Equations (6) and (7), into the Faraday equation for linear polarization resistance, as shown accordingly in Equation (8):

$$
\mathrm{CR}=\frac{0.13 \mathrm{I}_{\mathrm{corr}} \mathrm{W}_{\mathrm{eq}}}{\mathrm{d}}
$$

where $W_{\mathrm{eq}}$ is the equivalent weight and $\mathrm{d}$ is the density of the sample electrode, respectively.

For a clearer understanding regarding the influence of different substrates on the corrosion of the $\mathrm{Zn}$ anode, the potentiodynamic polarization of the $\mathrm{Zn} / \mathrm{IF}$ and $\mathrm{Zn} / \mathrm{NF}$ electrodes has been compared with the pure $\mathrm{Zn}$ plate anode. As revealed in Figure $5 \mathrm{a}$, the corrosion potential of $\mathrm{Zn}$ shifted negatively through the use of $\mathrm{Zn} / \mathrm{NF}$ but positively through the use of $\mathrm{Zn} / \mathrm{IF}$. This suggests that the $\mathrm{Zn} / \mathrm{IF}$ electrode further affected the anodic process of $\mathrm{Zn}$ corrosion in the electrolyte whereas $\mathrm{Zn} / \mathrm{NF}$ mainly affected 
the cathodic process. The lower corrosion potential via the use of NF corresponded with the more negative potential of hydrogen evolution, indicating that $\mathrm{Zn} / \mathrm{NF}$ can enhance the charge efficiency if used in $\mathrm{Zn}$-based batteries [39]. Moreover, the positive shift of $\mathrm{E}_{\mathrm{corr}}$ associated with the $\mathrm{Zn} / \mathrm{IF}$ electrode indicated that IF reduced the rates of the anode reactions. Thereby, it was seen to be effective in decreasing the corrosion susceptibility of the $\mathrm{Zn}$ anode. However, for both the $\mathrm{Zn} / \mathrm{IF}$ and $\mathrm{Zn} / \mathrm{NF}$ electrodes, cathodic and anodic branches shifted to higher current densities compared to the Zn plate while the shift was even bigger for the IF electrode. This suggested a higher rate of hydrogen evaluation and $\mathrm{Zn}$ dissolution associated with the use of porous electrodes. In Table 2, the polarization results are indicated, and the corrosion rate was calculated for each anode, accordingly. Higher corrosion current densities of $5.091 \mathrm{~mA} / \mathrm{cm}^{2}$ and $5.912 \mathrm{~mA} / \mathrm{cm}^{2}$ were attained for $\mathrm{Zn} / \mathrm{NF}$ and $\mathrm{Zn} / \mathrm{IF}$, respectively, as compared to the $\mathrm{I}_{\text {corr }}$ of $\mathrm{Zn}$ plate $\left(3.430 \mathrm{~mA} / \mathrm{cm}^{2}\right)$. The higher corrosion rates are indicators of lower polarization resistance, i.e., a lower corrosion inhibition property. Furthermore, both $\mathrm{Zn} / \mathrm{IF}$ and $\mathrm{Zn} / \mathrm{NF}$ electrodes exhibited a lower anodic slope of the Tafel curve than that of the $\mathrm{Zn}$ plate. The smaller slope indicated higher corrosion of the anode caused by higher kinetics of $\mathrm{Zn}$ dissolution in the electrolyte. In other words, corrosion on the $\mathrm{Zn}$ surface occurred due to the formation of a $\mathrm{ZnO}$ layer around the anode surface, which acted as a passivation layer and suppressed the dissolution of $\mathrm{Zn}$ ions in the electrolyte that eventually lowered the current density of the electrode. In addition, the hydrogen evolution in the cathodic branch of the $\mathrm{Zn} / \mathrm{IF}$ electrode was observed to be more intensive as compared with the $\mathrm{Zn}$ plate and $\mathrm{Zn} / \mathrm{NF}$, whereby the former agreed with the results of $\mathrm{CV}$, as shown in Figure 4a.
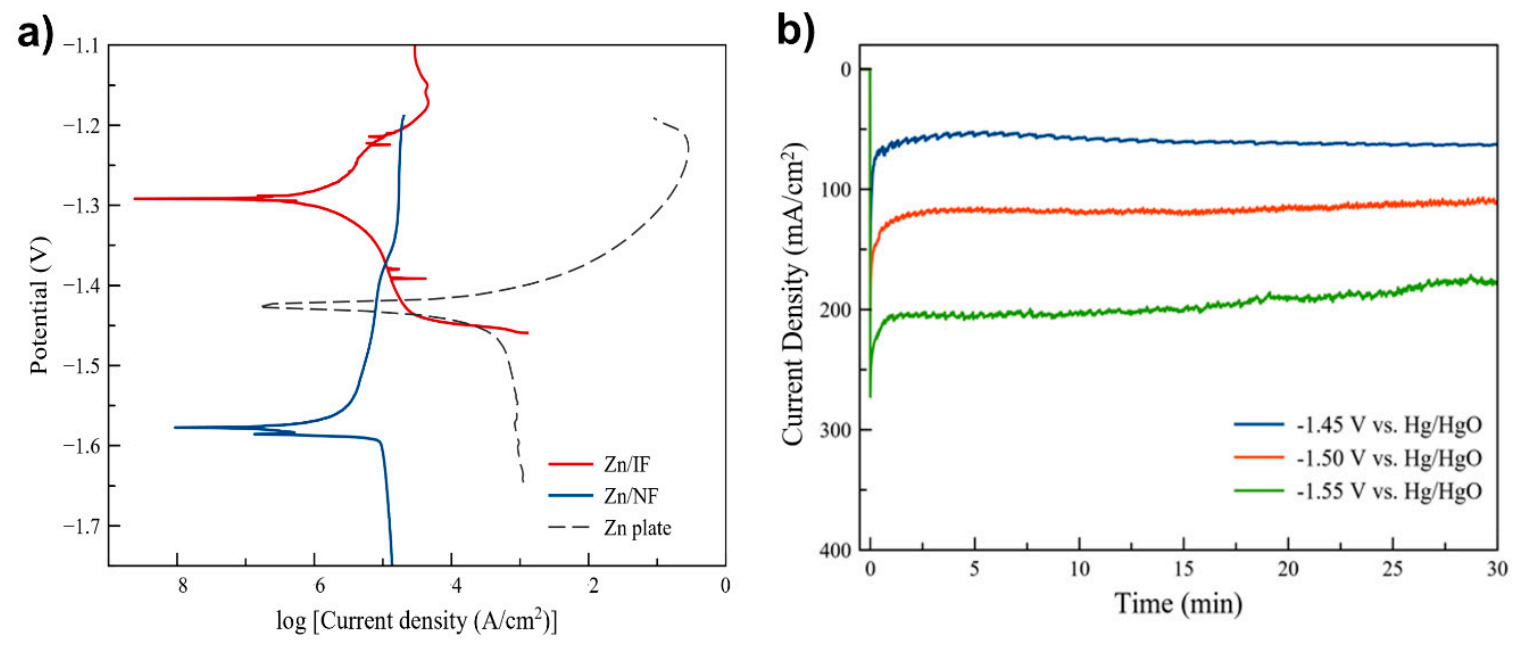

Figure 5. (a) Potentiodynamic polarization (Tafel) curves of the pure $\mathrm{Zn}$ plate, $\mathrm{Zn} / \mathrm{IF}$ and $\mathrm{Zn} / \mathrm{NF}$ anodes, at a scan rate of $1.67 \mathrm{mV} / \mathrm{s}$. (b) Chronoamperometry of the $\mathrm{Zn} / \mathrm{IF}$ electrode within a potential range of -1.45 to $-1.60 \mathrm{~V}$ vs. $\mathrm{Hg} / \mathrm{HgO}$ in an electrolyte solution.

In Figure $5 \mathrm{~b}$, the results of the chronoamperometry tests are shown. The $\mathrm{Zn} / \mathrm{IF}$ electrode was used to determine the $\mathrm{Zn}$ deposition influenced by an applied potential. At each selected potential, the current-time transient for $30 \mathrm{~min}$ was observed. In higher potentials, noisy curves appeared due to the non-homogeneous distribution of deposits on the surface of the electrode, as a result of HER [40]. Potentials were selected in the range of -1.45 to $-1.60 \mathrm{~V}$ vs. $\mathrm{Hg} / \mathrm{HgO}$ associated with the cathodic region, whereby the highest rate of deposition/dissolution close to the surface of the electrode was observed (see Figure 4a). Results revealed that the reduction of $\mathrm{Zn}$ had decreased at potentials below $-1.45 \mathrm{~V}$ vs. $\mathrm{Hg} / \mathrm{HgO}$. Moreover, the rising portion, which appeared at $0.025 \mathrm{~min}$, was due to the $\mathrm{Zn}$ nucleation process [41]. In more negative potentials, particularly at $-1.55 \mathrm{~V} \mathrm{vs}$. $\mathrm{Hg} / \mathrm{HgO}$, the current-time transition curve was non-smooth with currents being unstable. This was probably because of the smaller surface area and thus less conductivity of the electrode caused by the formation of hydrogen gas. This also suggests that more powerful reactions between the reduced electrode surface and hydrogen gas had taken place, which affected surface conductivity. Since water is a better 
electron recipient than zincate ion, introducing more energy to the process will cause the hydrogen from hydrolyzed water $\left(\mathrm{H}^{+}\right)$to take over the reaction with the released electron and to form $\mathrm{H}_{2}$. As a result, more HER occurred accordingly, as in Equations (9)-(11):

$$
\begin{gathered}
\mathrm{H}^{+}+\mathrm{e}^{-} \rightleftharpoons \mathrm{H}_{\mathrm{ads}} \\
\mathrm{H}_{\mathrm{ads}}+\mathrm{H}^{+}+\mathrm{e}^{-} \rightleftharpoons \mathrm{H}_{2} \\
\mathrm{H}_{\mathrm{ads}}+\mathrm{H}_{\mathrm{ads}} \rightleftharpoons \mathrm{H}_{2}
\end{gathered}
$$

To further conceptualize the charge transfer, the CV plots for both the Zn/IF and Zn/NF anodes were obtained at various scan rates (5 to 20 ) $\mathrm{mV} / \mathrm{s}$ in the electrolyte (Figure $6 \mathrm{a}, \mathrm{b}$ ). It is observed that when scan rates increased, the anodic peak currents linearly increased. However, the cathodic peaks are less dependent on the scan rate. Anodic peaks can be split into three distinct regions: charge transfer region, diffusion-controlled region and mixed charge transfer diffusion-controlled region. Typically, when current density changes linearly with the square root of the scan rate for the reduction process, this indicates that the peak is caused by ion diffusion. The effect of scan rate on the peak current $i_{c}$ for simple redox reactions can be described by the Randles-Sevcik equation, as shown in Equation (12):

$$
i_{c}=\left(2.99 \times 10^{5}\right) \mathrm{A} \alpha^{0.5} v^{0.5} \mathrm{D}_{0}^{0.5} \mathrm{C}_{0}
$$

where $i_{c}$ is the peak current density $\left(\mathrm{mA} / \mathrm{cm}^{2}\right), \alpha$ is the electron transfer coefficient, $\mathrm{D}_{0}$ is the diffusion coefficient $\left(\mathrm{cm}^{2} / \mathrm{s}\right), \mathrm{C}_{0}$ is concentration $\left(\mathrm{mol} / \mathrm{cm}^{3}\right), \mathrm{A}$ is the surface area $\left(\mathrm{cm}^{2}\right)$ and $v$ is the scan rate $(\mathrm{mV} / \mathrm{s})$. The fitted lines for the logarithmic values of anodic peaks, as a function of root square of scan rates, were plotted (Figure $6 \mathrm{~b}, \mathrm{c}$ ); the corresponding equations were derived accordingly, as shown in Equations (13) and (14):

$$
\begin{aligned}
\log \left(i_{c}\right) & =0.1085 \log v^{0.5}+2.492(\text { for } \mathrm{Zn} / \mathrm{IF} \text { electrode) } \\
\log \left(i_{c}\right) & =0.0261 \log v^{0.5}+2.476(\text { for } \mathrm{Zn} / \mathrm{NF} \text { electrode) }
\end{aligned}
$$

Thus, the straight lines revealed slopes of 0.1085 and 0.0261 for $\mathrm{Zn} / \mathrm{IF}$ and $\mathrm{Zn} / \mathrm{NF}$, respectively, which are lower than the theoretical value of 0.5 for a fully diffusion-controlled process.

As shown in Figures 7 and 8, the micrographs (200×) for Zn deposition on the active surface of IF and NF, after a $30 \mathrm{~min}$ duration, were studied at different potentials via SEM. As observed in Figure 7, from $-1.60 \mathrm{~V}$ vs $\mathrm{Hg} / \mathrm{HgO}\left(\right.$ at $-180.90 \mathrm{~mA} / \mathrm{cm}^{2}$ ) to $-1.45 \mathrm{~V}$ vs $\mathrm{Hg} / \mathrm{HgO}$ (at $-52.29 \mathrm{mAh} / \mathrm{cm}^{2}$ ) the sequential decline of potentials led to a reshaped IF electrode surface, changing from a dendritic thread-like morphology (Figure 7a) into a more compact solid form (Figure 7d). It is noted that the deposition of $\mathrm{Zn}$ ions at lower potentials was least affected by hydrogen evolution and occurred at a higher rate; hence, a more uniform surface was observed (Figure $7 \mathrm{~d}$ ). At a potential of $-1.60 \mathrm{~V}$ vs. $\mathrm{Hg} / \mathrm{HgO}$, the deposition of $\mathrm{Zn}$ ions developed the dendritic form of fibers (Figure 7a). At the potential of $-1.50 \mathrm{~V}$ vs. $\mathrm{Hg} / \mathrm{HgO}$ (at $-140.86 \mathrm{mAh} / \mathrm{cm}^{2}$ ), the surface was further covered with deposited substances; nevertheless, the individual particulate features can still be distinguished on the surface (Figure $7 b$ ). Lower potentials of -1.50 and $-1.45 \mathrm{~V}$ vs. $\mathrm{Hg} / \mathrm{HgO}$ induced further deposition of $\mathrm{Zn}$ ions, resulting in a relatively craggy appearance of the anode surface (Figure 7c,d). The SEM results were compared to $\mathrm{Zn}$ ions deposition on a structured porous surface of NF as presented in Figure 8. Thus, it was confirmed that, at higher potentials, $\mathrm{Zn}$ ions were distributed within the pores of the 3D scaffold structure of the bare NF, in the form of dendrites (Figure 8a). However, the deposition of Zn at lower potentials seemed to occur, in a regular fashion, with a three-dimensional growth inside the pores and, therefore, begins to develop a compact surface on the electrode (Figure $8 c, d$ ). Similar evolution on the texture of NF, as the result of electrodeposition, has been reported previously [42]. 
a)
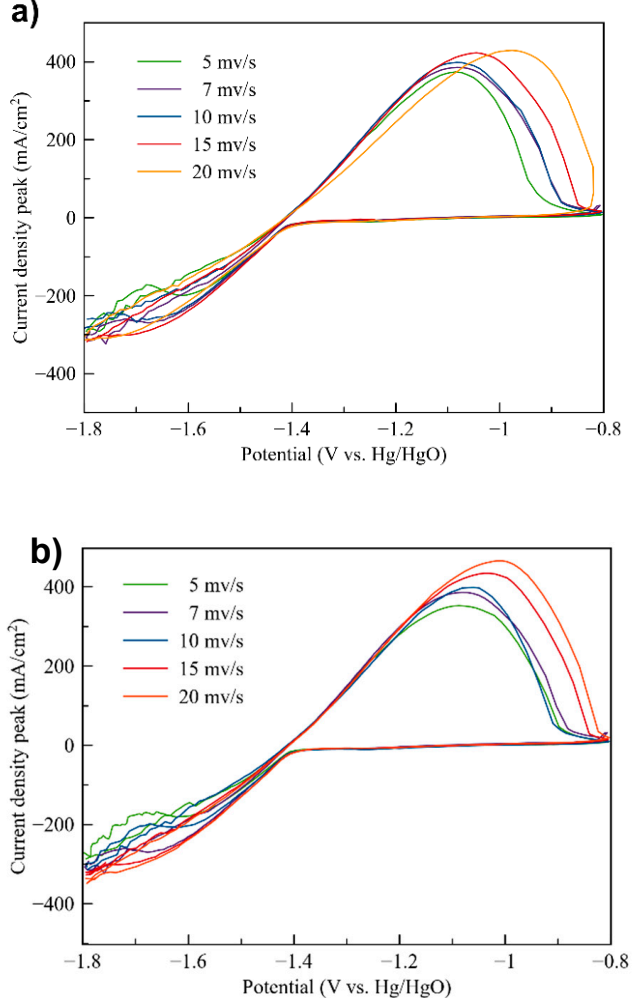

c)

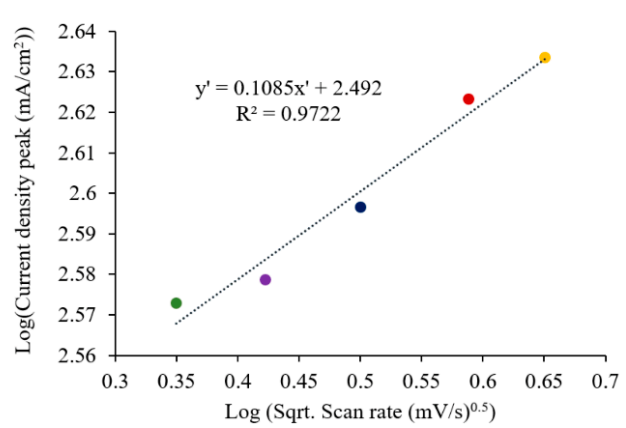

d)

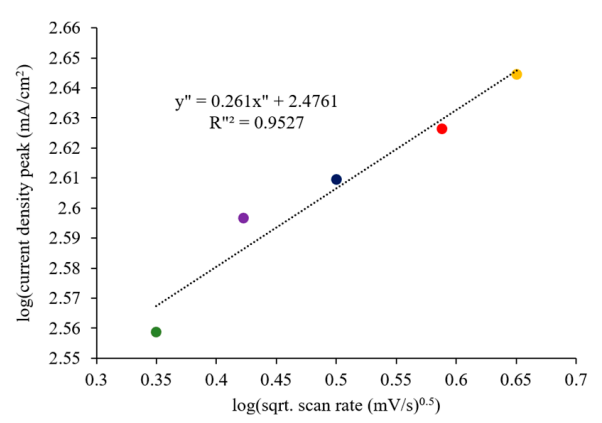

Figure 6. CV curves at different scan rates (5 to 20 ) $\mathrm{mV} / \mathrm{s}$ vs. current density for (a) $\mathrm{Zn} / \mathrm{IF}$ and (b) $\mathrm{Zn} / \mathrm{NF}$ electrodes in an electrolyte solution. Logarithmic current density peaks vs. logarithmic square root of scan rate with fitted line for (c) Zn/IF and (d) Zn/NF.
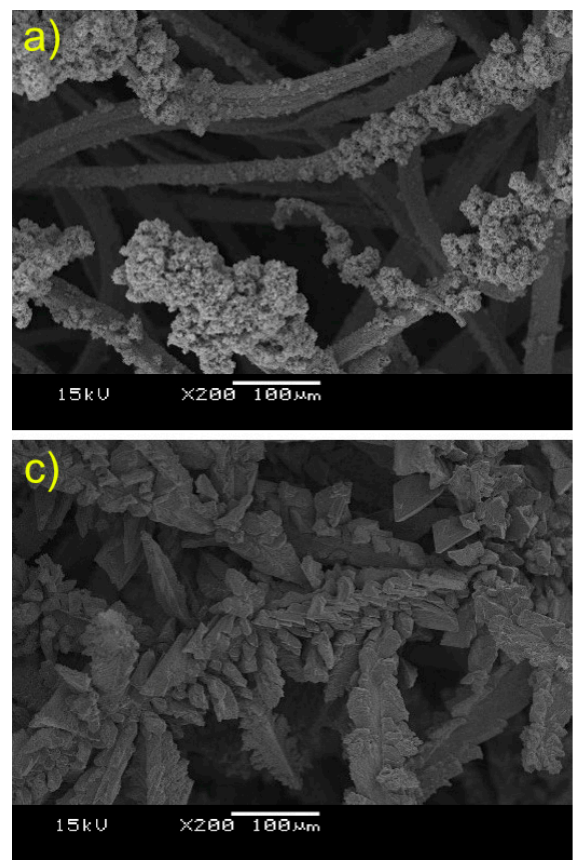
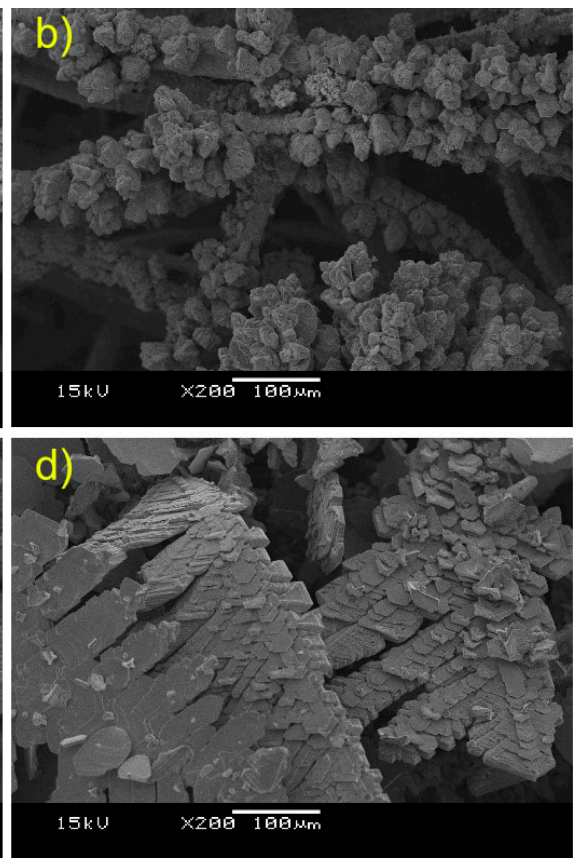

Figure 7. SEM micrographs of the $\mathrm{Zn} / \mathrm{IF}$ surface $(200 \times)$, at deposition potentials of (a) $-1.60 \mathrm{~V}$ vs. $\mathrm{Hg} / \mathrm{HgO},(\mathbf{b})-1.55 \mathrm{~V}$ vs. $\mathrm{Hg} / \mathrm{HgO}$, (c) $-1.50 \mathrm{~V}$ vs. $\mathrm{Hg} / \mathrm{HgO}$ and $(\mathbf{d})-1.45 \mathrm{~V}$ vs. $\mathrm{Hg} / \mathrm{HgO}$ for $30 \mathrm{~min}$ in an electrolyte solution. 

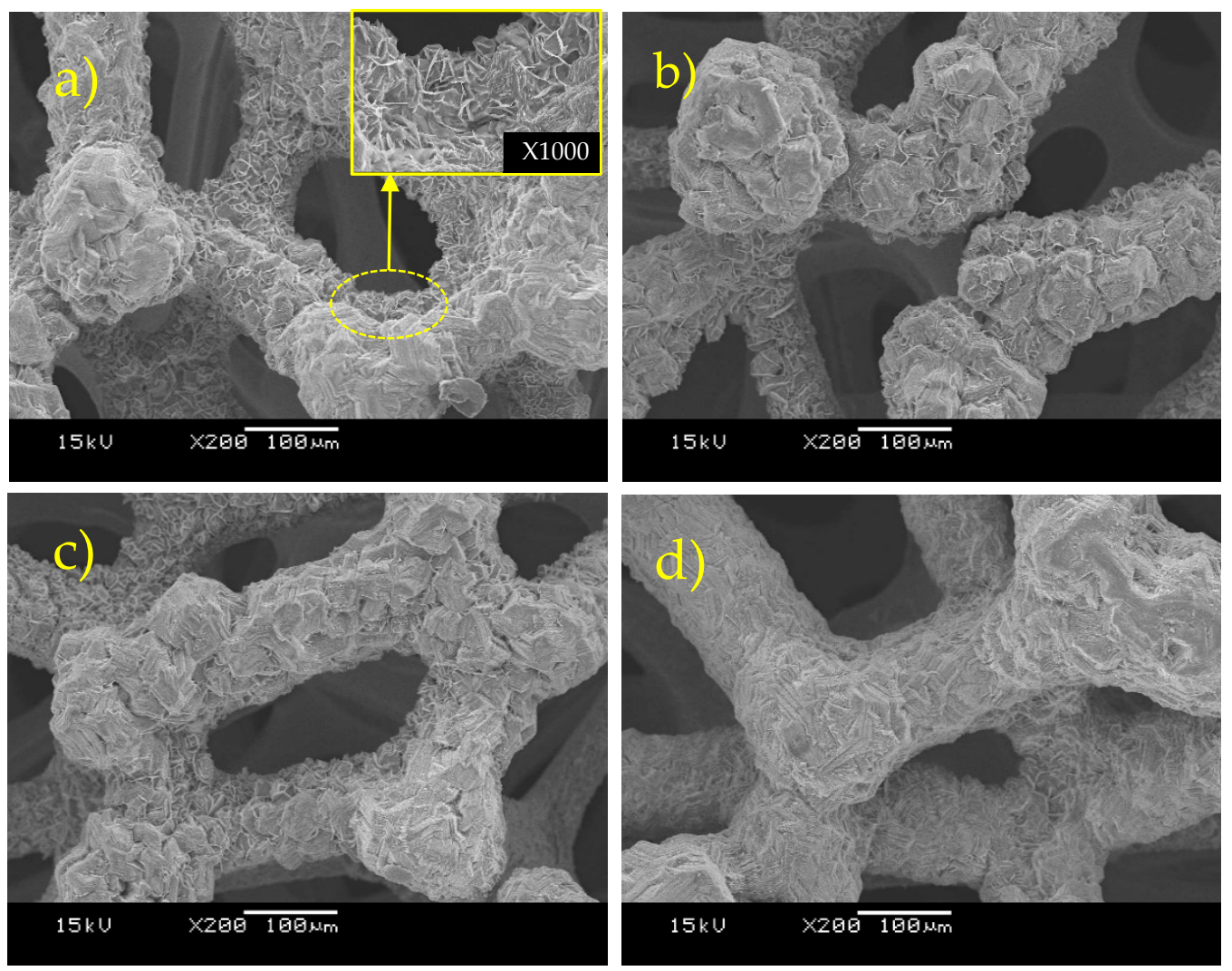

Figure 8. SEM micrographs of the $\mathrm{Zn} / \mathrm{NF}$ surface (200×), at deposition potentials of (a) $-1.60 \mathrm{~V}$ vs. $\mathrm{Hg} / \mathrm{HgO}$ (inset 1000x), (b) $-1.55 \mathrm{~V}$ vs. $\mathrm{Hg} / \mathrm{HgO}$, (c) $-1.50 \mathrm{~V}$ vs. $\mathrm{Hg} / \mathrm{HgO}$ and (d) $-1.45 \mathrm{~V}$ vs. $\mathrm{Hg} / \mathrm{HgO}$ for $30 \mathrm{~min}$ in a $(1 \mathrm{M}) \mathrm{Zn}$ sulfate electrolyte solution.

The application of the IF anode exhibited different characteristics of $\mathrm{Zn}$ ions deposition as well as dendrite formation along the thin and straight fibers, at slightly higher levels of current density.

EDX analysis, as shown in Figures S2 and S3, confirms the presence of Zn elements after electrodeposition on both electrode surfaces, indicating that $\mathrm{Zn}$ deposition increases at higher current densities/lower potentials. Furthermore, BET analysis revealed that $\mathrm{Zn}$ electrodeposition, at a potential of $-1.45 \mathrm{~V}$. vs. $\mathrm{Hg} / \mathrm{HgO}$ for the duration of $30 \mathrm{~min}$ in a $(1 \mathrm{M}) \mathrm{ZnSo}_{4}$ electrolyte solution, caused an increase in the surface area of both electrodes, from 0.07 and $1.20 \mathrm{~m}^{2} / \mathrm{g}$ to $0.90 \mathrm{~m}^{2} / \mathrm{g}$ and $4.09 \mathrm{~m}^{2} / \mathrm{g}$ for IF and NF substrates, respectively (see Table S1).

The results of electrochemical analysis indicated that the $\mathrm{Zn} / \mathrm{IF}$ electrode performed in a similar manner to the conventional $\mathrm{Zn} / \mathrm{NF}$ electrode. According to $\mathrm{CV}$ analysis, the $\mathrm{Zn} / \mathrm{IF}$ electrode revealed a comparable mechanism of $\mathrm{Zn}$ dissolution/deposition with the $\mathrm{Zn} / \mathrm{NF}$ electrode. Although the surface of $\mathrm{Zn} / \mathrm{IF}$ is susceptible to corrosion via hydrogen evolution, the impact can be diminished when using additives to the electrolyte solution [32]. Furthermore, the IF electrode displayed a noticeably low charge transfer resistance and, hence, proved to be a preferable substitute to the conventional NF in the synthesis of the porous anode.

\subsection{Performances of $\mathrm{Zn}$ Electrodes in a $\mathrm{ZAB}$}

The electrostatic charge/discharge performance of $\mathrm{Zn} / \mathrm{IF}$ electrode was evaluated for cyclic stability and cycle lifespan using a ZAB. For a more precise observation, the results were compared with the performance of a $\mathrm{Zn} / \mathrm{NF}$ electrode in a very similar experimental condition. Basically, the extended cycling performance of the ZAB was investigated when the cell was charging with a constant current of $10 \mathrm{~mA} / \mathrm{cm}^{2}$ for $160 \mathrm{~s}$ followed by resting for $60 \mathrm{~s}$ and then discharging under a constant current density of $10 \mathrm{~mA} / \mathrm{cm}^{2}$ to a cut-off voltage of $0.8 \mathrm{~V}$. The CE and round-trip efficiency (RTE) were 
calculated accordingly within 200 cycles. In Figure 9 the results are presented. For both electrodes, CE remained between $64 \%$ and $85 \%$ with average values of $78 \%$ and $80 \%$ for $\mathrm{Zn} / \mathrm{IF}$ and $\mathrm{Zn} / \mathrm{NF}$, respectively. The fluctuated values of $\mathrm{CE}$ can be ascribed to $\mathrm{ZnO}$ precipitation and zincate ions crossover, which could impede overall rechargeable performance. Furthermore, the energy efficiency of $\mathrm{Zn} / \mathrm{IF}$ ( $\sim 39 \%$ on average) is slightly less than that of $\mathrm{Zn} / \mathrm{NF}$ ( $\sim 43 \%$ on average). This may be due to the sluggish kinetics of redox reaction corresponding to the higher internal resistance of $\mathrm{Zn} / \mathrm{IF}$, which eventually hinders energy output and decreases RTE.

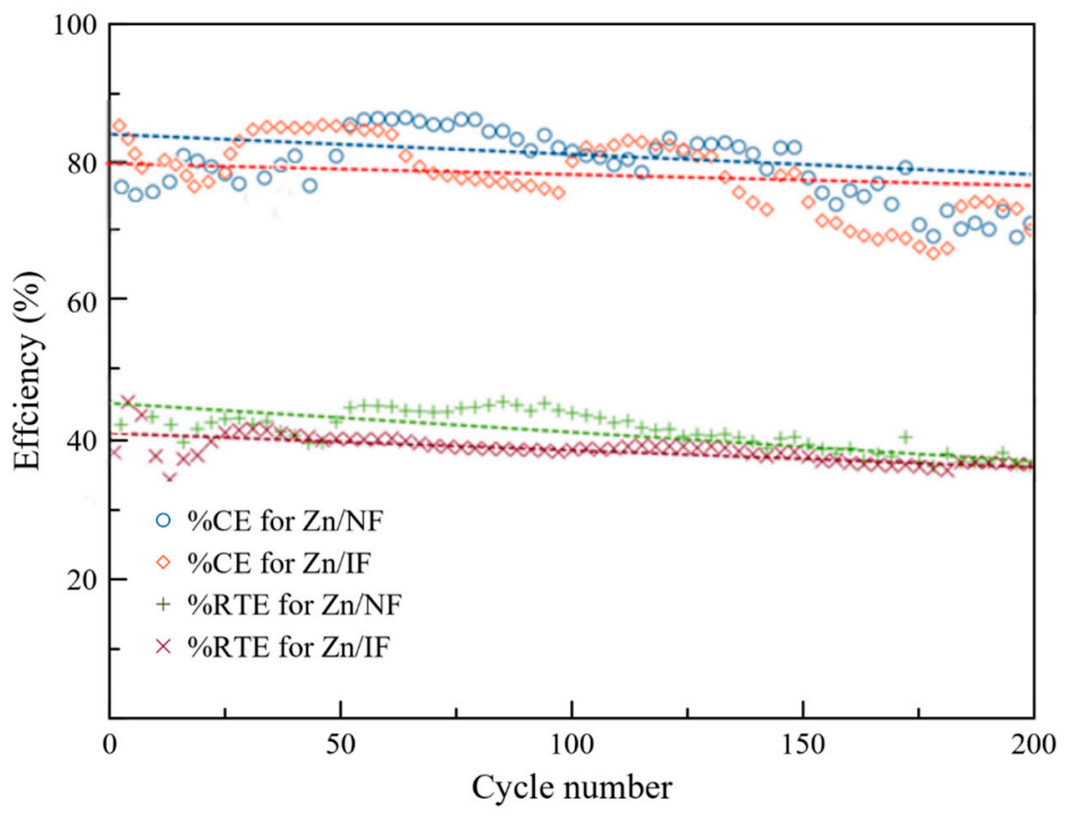

Figure 9. The coulombic efficiency (CE) and round-trip efficiency (RTE) of electrostatic charge/discharge performance of a ZAB with Zn/IF and Zn/NF anodes within 200 cycles.

Typically, improving the solubility of $\mathrm{ZnO}$ in $\mathrm{KOH}$ can increase the average RTE and reduce the passivation of the $\mathrm{Zn}$ anode in an alkaline electrolyte [38]. As reported in a previous study, for a ZAB, RTE was enhanced through a newly designed catalytic dual-layer of a composite oxygen electrode, which could accelerate and catalyze the reaction of oxygen evolution at a lower potential range and achieved an RTE of $72.2 \%$ [43].

Figure 10 demonstrates that both electrodes generated stable and coincident charge/discharge profiles, similar to a typical ZAB having a porous $\mathrm{Zn}$ anode [44]. At the 50th and 100th cycle, the $\mathrm{Zn} / \mathrm{IF}$ electrode exhibited a relatively lower discharge potential than the $\mathrm{Zn} / \mathrm{NF}$ electrode as well as a lower capacity, in a shorter discharge period, resulting in a totally lower discharge performance. However, at the 200th cycle, the capacity of the battery with the $\mathrm{Zn} / \mathrm{IF}$ electrode almost reached $1.48 \mathrm{mAh}$ comparable to the $\mathrm{Zn} / \mathrm{NF}$ electrode, at the same discharge period. Moreover, the intensive rise in charge potential and noticeably low capacity of the $\mathrm{Zn} / \mathrm{NF}$ electrode in the 1st cycle can be ascribed to the instantaneous generation of hydrogen gas at the electrode/electrolyte interface. It was also observed that there were voltage plateaus in the charge/discharge curves. However, the shorter plateaus of the discharge curves can be attributed to the $\mathrm{ZnO}$ (that is formed during the discharge process) that acted as an insulator and passivated the $\mathrm{Zn}$ surface, thereby increasing the internal resistance of the battery [45].

Furthermore, the effect of charge-discharge cycling on the internal resistance of electrodes were investigated. Multicycle CV was implemented at a scan rate of $0.07 \mathrm{mV} / \mathrm{s}$ at vertex potentials $\pm 0.5 \mathrm{~V}$ vs. OCV for each electrode, in an electrolyte solution. A pure $\mathrm{Zn}$ plate of $1 \times 1 \mathrm{~cm}^{2}$ was used as counter electrode. An open cell was employed to ensure that the generated hydrogen gas consistently discharged from the cell, thereby not imposing additional resistance at the electrodes/electrolyte interface. After every 50th cycle, the CV measurement was interrupted and EIS analysis was performed 
at a frequency range from $100 \mathrm{kHz}$ to $0.1 \mathrm{~Hz}$ with an alternate current amplitude of $10 \mathrm{mV}$ around OCV; for Nyquist and Bode plots, see Figure S4a-f. In Figure 11a,b, Nyquist plots are shown at the initial state and at the 200th cycle. The equivalent circuit also used for fitting of the EIS plots and the fitted data for all circuit elements is shown in Table 3. The presence of an inductive part (L) at high frequencies is commonly related to the cables and connections [46]. The values of $R_{\mathrm{s}}$ were found to be relatively low for both cells after 200 cycles $(<3 \Omega)$, indicating a high electrochemical cycling stability presented by both electrodes. The increased $R_{s}$ after 200 cycles corresponds to an increase in internal resistance of the electrodes. The increment of $R_{s}$ occurred with a lower magnitude when $\mathrm{Zn} / \mathrm{NF}$ was used $(\sim 54 \%)$ than when $\mathrm{Zn} / \mathrm{IF}$ was used $(\sim 100 \%)$, indicating that the internal resistance of the latter was more affected by morphological deterioration and reduced number of $\mathrm{Zn}$ ions on electrode surface. Moreover, for both cells, The $\mathrm{R}_{\mathrm{ct}}$ was found to be decreased after 200 cycles suggesting that the ion transfer was easily facilitated, and reversibility was improved through charge-discharge cycling. The more significant reduction of $\mathrm{R}_{\mathrm{ct}}$ associated with the cell involved $\mathrm{Zn} / \mathrm{IF}(\sim 81 \%)$ than $\mathrm{Zn} / \mathrm{NF}$ $(\sim 57 \%)$ suggests that the contact area was increased, and hence faster ion transport occurred at the electrode-electrolyte interface during charge-discharge cycling. The increased contact area can be ascribed to the less stability, and hence deterioration of passivation layer when increasing the number of cycles. The deteriorated passivation layer causes the active sites on the electrode to expose more to the electrolyte and thus enhance the kinetics of the charge transfer process.
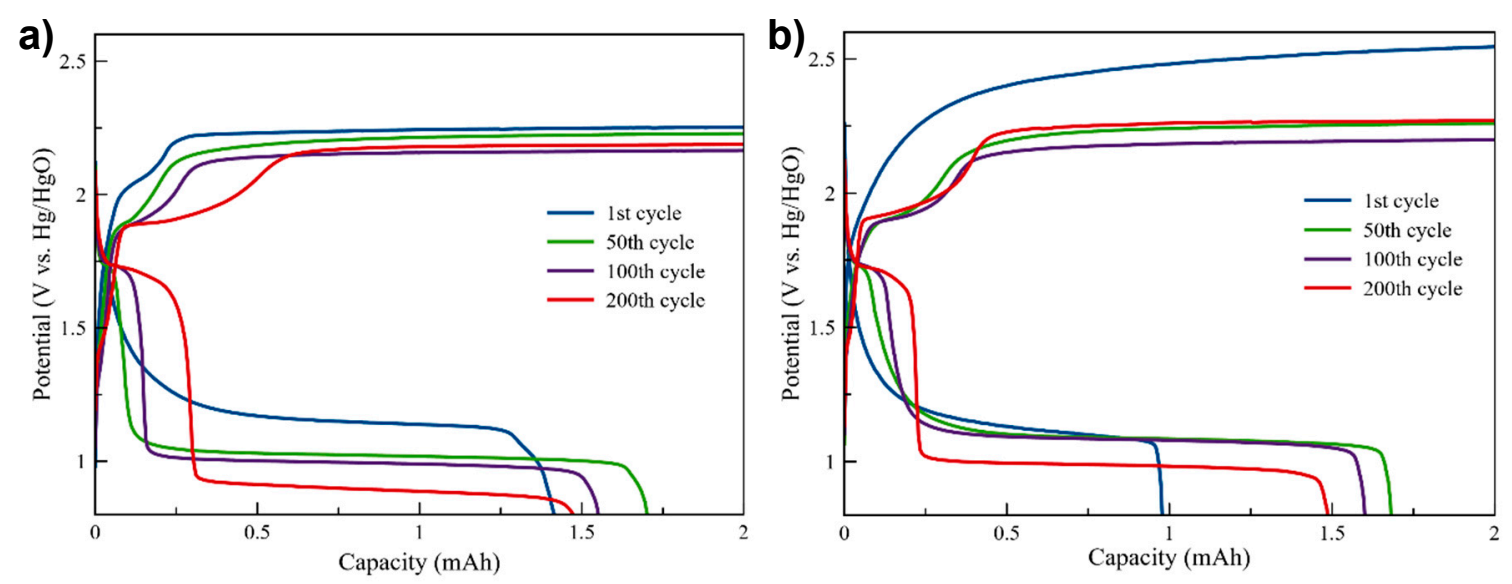

Figure 10. Charge and discharge performances of the $\mathrm{ZAB}$ under $10 \mathrm{~mA} / \mathrm{cm}^{2}$ in electrolyte solution at the 1st, 50th, 100th and 200th cycle for (a) Zn/IF and (b) Zn/NF electrodes.

a)

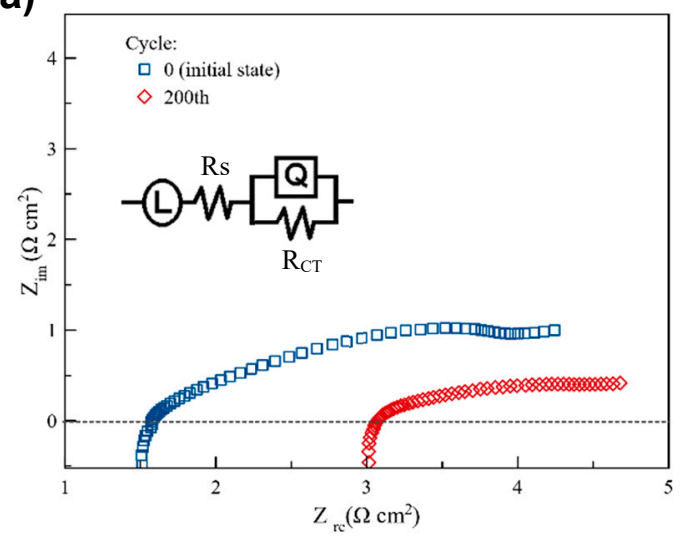

b)

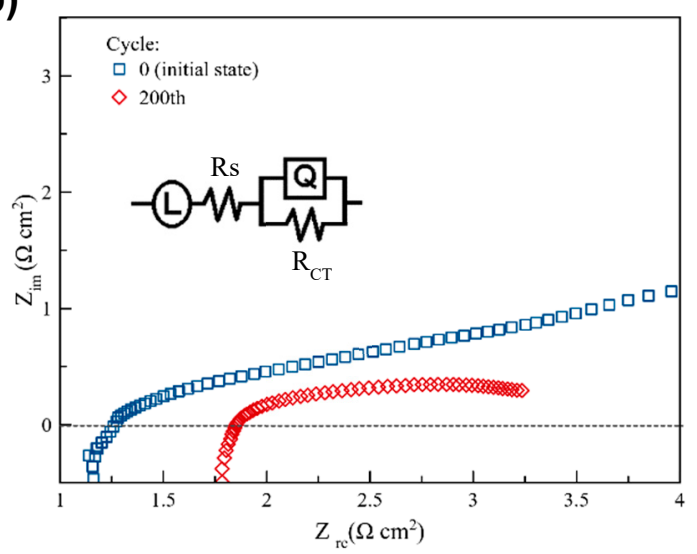

Figure 11. Nyquist plots of cycling impact on cell impedance when using (a) Zn/IF and (b) Zn/NF electrodes at the initial state $(t=0)$ and after the 200th charge-discharge cycle at a frequency range from $100 \mathrm{kHz}$ to $0.1 \mathrm{~Hz}$ with an alternate current amplitude of $10 \mathrm{mV}$ around OCV. 
Table 3. Resistance values of $\mathrm{Zn}$ anodes in the electrolyte at initial state $(t=0)$ and after the 200th charge-discharge cycle.

\begin{tabular}{ccccc}
\hline Component & Zn/IF $(t=0)$ & Zn/IF (200th Cycle) & Zn/NF $(t=0)$ & Zn/NF (200th Cycle) \\
\hline $\mathbf{L} \times \mathbf{1 0}^{\mathbf{7}}(\boldsymbol{\Omega})$ & 2.065 & 1.874 & 2.197 & 2.149 \\
$\operatorname{Rs}(\Omega)$ & 1.489 & 2.967 & 1.142 & 1.761 \\
$\mathbf{R}_{\mathrm{CT}}(\boldsymbol{\Omega})$ & 8.220 & 1.510 & 7.500 & 3.205 \\
\hline
\end{tabular}

\section{Conclusions}

In this work, it was noted that substituting the conventional NF with IF, as an anode current collector for ZABs, was found to be feasible. This was because it performed with almost comparable electrochemical properties as NF. According to EIS analysis, the use of Zn/IF was found to improve the charge transfer of the anode. Potentiodynamic polarization revealed that IF reduced the rates of anode reactions and it was effective in decreasing the corrosion susceptibility of the $\mathrm{Zn}$ anode. All electrochemical characterization and measurements agreed that the $\mathrm{Zn} / \mathrm{IF}$ electrode was able to compete with the conventional NF-based electrode in terms of performance and characteristics. When used in a ZAB, IF exhibited a relatively comparable charge/discharge performance to the NF electrode. The Zn/IF electrode exhibited comparable CE and RTE to the Zn/NF electrode. Moreover, the evolution of electrode impedance with charge-discharge cycling was investigated and the results of EIS revealed that $\mathrm{Zn} / \mathrm{IF}$ could significantly reduce the charge transfer resistance after 200 cycles, even at a higher magnitude than the $\mathrm{Zn} / \mathrm{NF}$ electrode. Thus, considering its lower cost, the $\mathrm{Zn} / \mathrm{IF}$ electrode was found to be a valuable replacement for NF in the fabrication of ZABs.

Supplementary Materials: The following are available online at http://www.mdpi.com/1996-1073/13/6/1429/s1, Table S1: Surface area, pore volume, and average pore diameter $\left(\mathrm{N}_{2}\right.$ adsorption-desorption isotherm) of different bare and anode samples. Figure S1: Bode diagrams of fitted EIS lines at a starting frequency of $100 \mathrm{kHz}$ to $0.1 \mathrm{~Hz}$ for (a) $\mathrm{Zn} / \mathrm{IF}$ and (b) Zn/NF electrode around OCV in electrolyte solution. Figure S2: EDX of zinc electrodeposition on IF at potential of $(\mathbf{a})-1.60 \mathrm{~V}$ vs. $\mathrm{Hg} / \mathrm{HgO},(\mathbf{b})-1.55 \mathrm{~V}$ vs. $\mathrm{Hg} / \mathrm{HgO},(\mathbf{c})-1.50 \mathrm{~V}$ vs. $\mathrm{Hg} / \mathrm{HgO}$ and (d) $-1.45 \mathrm{~V}$ vs. $\mathrm{Hg} / \mathrm{HgO}$. Figure S3: EDX of zinc electrodeposition on $\mathrm{NF}$ at potential of (a) $-1.60 \mathrm{~V}$ vs. $\mathrm{Hg} / \mathrm{HgO},(\mathbf{b})-1.55 \mathrm{~V}$ vs. $\mathrm{Hg} / \mathrm{HgO}$, (c) $-1.50 \mathrm{~V}$ vs. $\mathrm{Hg} / \mathrm{HgO}$ and (d) $-1.45 \mathrm{~V}$ vs. $\mathrm{Hg} / \mathrm{HgO}$. Figure S4: Evolution of cell impedance at initial stage and after 50th, 100th, 150th and 200th charge-discharge cycle: (a) Nyquist plots when used Zn/IF, (b) Nyquist plots when used Zn/NF, (c) BOD diagram when used Zn/IF at initial state $(t=0)$, (d) BOD diagram when used $\mathrm{Zn} / \mathrm{IF}$ at 200th cycle, (e) BOD diagram when used $\mathrm{Zn} / \mathrm{NF}$ at initial state $(\mathrm{t}=0)$, (f) BOD diagram when used $\mathrm{Zn} / \mathrm{NF}$ at 200th cycle at a frequency range from $100 \mathrm{kHz}$ to $0.1 \mathrm{~Hz}$ with an alternate current amplitude of $10 \mathrm{mV}$ around OCV.

Author Contributions: Conceptualization, S.K.; methodology, S.K., A.A. and R.K.; investigation, K.J. and R.K.; formal analysis, K.J., R.K., A.A., A.A.M. and S.K.; writing-original draft preparation, R.K.; writing-review and editing, R.K., T.M., A.A.M. and S.K.; supervision, S.K.; funding acquisition, S.K.; project administration, S.K. All authors have read and agreed to the published version of the manuscript.

Funding: Chulalongkorn Academic Advancement into its Second Century Project, and the Energy Storage Cluster of Chulalongkorn University are acknowledged.

Acknowledgments: R.K. and A.A. acknowledge the support from Chulalongkorn Academic Advancement into its 2nd Century Project for Postdoctoral Fellowship. The authors thank Prof. Sigurd Skogestad for his comments and the support from Rachadapisek Sompote Fund, Chulalongkorn University for his stay in Bangkok.

Conflicts of Interest: The authors declare no conflict of interest. 


\section{Abbreviations}

$\begin{array}{ll}\text { CV } & \text { Cyclic voltammetry } \\ \text { CR } & \text { Corrosion rate } \\ \text { CE } & \text { Coulombic efficiency } \\ \text { EIS } & \text { Electrochemical impedance spectroscopy } \\ \text { EESS } & \text { Electrical energy storage system } \\ \mathrm{E}_{\text {corr }} & \text { Corrosion potential } \\ \text { HER } & \text { Hydrogen evolution reaction } \\ \mathrm{I}_{\text {corr }} & \text { Corrosion current density } \\ \mathrm{IF} & \text { Iron fibers } \\ \mathrm{NF} & \text { Nickel foam } \\ \mathrm{ORR} & \text { Oxygen reduction reaction } \\ \mathrm{RTE} & \text { Round-trip efficiency } \\ \mathrm{SEM} & \text { Scanning electron microscope } \\ \mathrm{ZAB} & \text { Zinc-air battery } \\ \mathrm{Zn} / \mathrm{IF} & \text { Zinc electrodeposited on iron fibers } \\ \mathrm{Zn} / \mathrm{NF} & \text { Zinc electrodeposited on nickel foam } \\ \mathrm{Zn} / \mathrm{Cu} & \text { Zinc adhered on copper plate }\end{array}$

\section{References}

1. Chen, H.; Cong, T.N.; Yang, W.; Tan, C.; Li, Y.; Ding, Y. Progress in electrical energy storage system: A critical review. Prog. Nat. Sci. 2009, 19, 291-312. [CrossRef]

2. Etxeberria, A.; Vechiu, I.; Camblong, H.; Vinassa, J.M. Comparison of three topologies and controls of a hybrid energy storage system for microgrids. Energy Convers. Manag. 2012, 54, 113-121. [CrossRef]

3. Wade, N.S.; Taylor, P.C.; Lang, P.D.; Jones, P.R. Evaluating the benefits of an electrical energy storage system in a future smart grid. Energy Policy 2010, 38, 7180-7188. [CrossRef]

4. Wu, X.; Song, K.; Zhang, X.; Hu, N.; Li, L.; Li, W.; Zhang, L.; Zhang, H. Safety Issues in Lithium Ion Batteries: Materials and Cell Design. Front. Energy Res. 2019, 7. [CrossRef]

5. Zeng, X.; Li, J.; Liu, L. Solving spent lithium-ion battery problems in China: Opportunities and challenges. Renew. Sustain. Energy Rev. 2015, 52, 1759-1767. [CrossRef]

6. Liu, K.; Liu, Y.; Lin, D.; Pei, A.; Cui, Y. Materials for lithium-ion battery safety. Sci. Adv. 2018, 4, eaas9820. [CrossRef]

7. Olivetti, E.A.; Ceder, G.; Gaustad, G.G.; Fu, X. Lithium-Ion Battery Supply Chain Considerations: Analysis of Potential Bottlenecks in Critical Metals. Joule 2017, 1, 229-243. [CrossRef]

8. Gaines, L. The future of automotive lithium-ion battery recycling: Charting a sustainable course. Sustain. Mater. Technol. 2014, 1-2, 2-7. [CrossRef]

9. Huang, K.D.; Sangeetha, T.; Cheng, W.F.; Lin, C.; Chen, P.T. Computational Fluid Dynamics Approach for Performance Prediction in a Zinc-Air Fuel Cell. Energies 2018, 11, 2185. [CrossRef]

10. Parker, J.F.; Chervin, C.N.; Pala, I.R.; Machler, M.; Burz, M.F.; Long, J.W.; Rolison, D.R. Rechargeable nickel-3D zinc batteries: An energy-dense, safer alternative to lithium-ion. Science 2017, 356, 415-418. [CrossRef]

11. Abbasi, A.; Hosseini, S.; Somwangthanaroj, A.; Mohamad, A.A.; Kheawhom, S. Poly(2,6-Dimethyl-1,4-Phenylene Oxide)-Based Hydroxide Exchange Separator Membranes for Zinc-Air Battery. Int. J. Mol. Sci. 2019, 20, 3678. [CrossRef] [PubMed]

12. Nitta, N.; Yushin, G. High-Capacity Anode Materials for Lithium-Ion Batteries: Choice of Elements and Structures for Active Particles. Part. Part. Syst. Charact. 2014, 31, 317-336. [CrossRef]

13. Bernardes, A.M.; Espinosa, D.C.R.; Tenório, J.A.S. Recycling of batteries: A review of current processes and technologies. J. Power Sources 2004, 130, 291-298. [CrossRef]

14. Lao-atiman, W.; Bumroongsil, K.; Arpornwichanop, A.; Bumroongsakulsawat, P.; Olaru, S.; Kheawhom, S. Model-Based Analysis of an Integrated Zinc-Air Flow Battery/Zinc Electrolyzer System. Front. Energy Res. 2019, 7, 15. [CrossRef] 
15. Poolnapol, L.; Kao-ian, W.; Somwangthanaroj, A.; Mahlendorf, F.; Nguyen, M.T.; Yonezawa, T.; Kheawhom, S. Silver Decorated Reduced Graphene Oxide as Electrocatalyst for Zinc-Air Batteries. Energies 2020, $13,462$. [CrossRef]

16. Wongrujipairoj, K.; Poolnapol, L.; Arpornwichanop, A.; Suren, S.; Kheawhom, S. Suppression of zinc anode corrosion for printed flexible zinc-air battery. Phys. Status Solidi $b$ 2017, 254, 1600442. [CrossRef]

17. Lee, C.W.; Sathiyanarayanan, K.; Eom, S.W.; Yun, M.S. Novel alloys to improve the electrochemical behavior of zinc anodes for zinc/air battery. J. Power Sources 2006, 160, 1436-1441. [CrossRef]

18. Kang, Z.; Wu, C.; Dong, L.; Liu, W.; Mou, J.; Zhang, J.; Chang, Z.; Jiang, B.; Wang, G.; Kang, F.; et al. 3D Porous Copper Skeleton Supported Zinc Anode toward High Capacity and Long Cycle Life Zinc Ion Batteries. ACS Sustain. Chem. Eng. 2019, 7, 3364-3371. [CrossRef]

19. Fan, Z.; Yan, J.; Ning, G.; Wei, T.; Zhi, L.; Wei, F. Porous graphene networks as high performance anode materials for lithium ion batteries. Carbon 2013, 60, 558-561. [CrossRef]

20. Lu, J.; Xiong, T.; Zhou, W.; Yang, L.; Tang, Z.; Chen, S. Metal Nickel Foam as an Efficient and Stable Electrode for Hydrogen Evolution Reaction in Acidic Electrolyte under Reasonable Overpotentials. ACS Appl. Mater. Interfaces 2016, 8, 5065-5069. [CrossRef]

21. Pierozynski, B.; Mikolajczyk, T.; Kowalski, I.M. Hydrogen evolution at catalytically-modified nickel foam in alkaline solution. J. Power Sources 2014, 271, 231-238. [CrossRef]

22. Elshkaki, A.; Reck, B.K.; Graedel, T.E. Anthropogenic nickel supply, demand, and associated energy and water use. Resour. Conserv. Recycl. 2017, 125, 300-307. [CrossRef]

23. Chen, T.; Jia, W.; Yao, Z.; Liu, Y.; Guan, X.; Li, K.; Xiao, J.; Liu, H.; Chen, Y.; Zhou, Y.; et al. Partly lithiated graphitic carbon foam as 3D porous current collectors for dendrite-free lithium metal anodes. Electrochem. Commun. 2019, 107, 106535. [CrossRef]

24. Garcia, A.; Norambuena-Contreras, J.; Bueno, M.; Partl, M. Influence of Steel Wool Fibers on the Mechanical, Termal, and Healing Properties of Dense Asphalt Concrete. J. Test. Eval. 2014, 42, 1107-1118. [CrossRef]

25. Cheng, Y.; Zhang, H.; Lai, Q.; Li, X.; Shi, D.; Zhang, L. A high power density single flow zinc-nickel battery with three-dimensional porous negative electrode. J. Power Sources 2013, 241, 196-202. [CrossRef]

26. Zhang, X.G. Fibrous zinc anodes for high power batteries. J. Power Sources 2006, 163, 591-597. [CrossRef]

27. Müller, S.; Holzer, F.; Haas, O. Optimized zinc electrode for the rechargeable zinc-air battery. J. Appl. Electrochem. 1998, 28, 895-898. [CrossRef]

28. Minakshi, M.; Appadoo, D.; Martin, D.E. The Anodic Behavior of Planar and Porous Zinc Electrodes in Alkaline Electrolyte. Electrochem. Solid-State Lett. 2010, 13, A77-A80. [CrossRef]

29. Hosseini, S.; Han, S.J.; Arponwichanop, A.; Yonezawa, T.; Kheawhom, S. Ethanol as an electrolyte additive for alkaline zinc-air flow batteries. Sci. Rep. 2018, 8, 11273. [CrossRef]

30. Weinrich, H.; Durmus, Y.E.; Tempel, H.; Kungl, H.; Eichel, R.-A. Silicon and Iron as Resource-Efficient Anode Materials for Ambient-Temperature Metal-Air Batteries: A Review. Materials 2019, 12, 2134. [CrossRef]

31. Li, X.; Li, D.; Qiao, L.; Wang, X.; Sun, X.; Wang, P.; He, D. Interconnected porous MnO nanoflakes for high-performance lithium ion battery anodes. J. Mater. Chem. 2012, 22, 9189-9194. [CrossRef]

32. Hosseini, S.; Lao-atiman, W.; Han, S.J.; Arpornwichanop, A.; Yonezawa, T.; Kheawhom, S. Discharge Performance of Zinc-Air Flow Batteries Under the Effects of Sodium Dodecyl Sulfate and Pluronic F-127. Sci. Rep. 2018, 8, 14909. [CrossRef]

33. Zhao, T.; Jiang, H.; Ma, J. Surfactant-assisted electrochemical deposition of $\alpha$-cobalt hydroxide for supercapacitors. J. Power Sources 2011, 196, 860-864. [CrossRef]

34. Asghari, S.; Mokmeli, A.; Samavati, M. Study of PEM fuel cell performance by electrochemical impedance spectroscopy. Int. J. Hydrogen Energy 2010, 35, 9283-9290. [CrossRef]

35. El-Sayed, A.-R.; Mohran, H.S.; Abd El-Lateef, H.M. Corrosion Study of Zinc, Nickel, and Zinc-Nickel Alloys in Alkaline Solutions by Tafel Plot and Impedance Techniques. Metall. Mater. Trans. A 2012, 43, 619-632. [CrossRef]

36. Parker, J.F.; Nelson, E.S.; Wattendorf, M.D.; Chervin, C.N.; Long, J.W.; Rolison, D.R. Retaining the 3D Framework of Zinc Sponge Anodes upon Deep Discharge in Zn-Air Cells. ACS Appl. Mater. Interfaces 2014, 6, 19471-19476. [CrossRef]

37. Matthews, D. The Stern-Geary and related methods for determining corrosion rates. Aust. J. Chem. 1975, 28, 243-251. [CrossRef] 
38. Hosseini, S.; Abbasi, A.; Uginet, L.-O.; Haustraete, N.; Praserthdam, S.; Yonezawa, T.; Kheawhom, S. The Influence of Dimethyl Sulfoxide as Electrolyte Additive on Anodic Dissolution of Alkaline Zinc-Air Flow Battery. Sci. Rep. 2019, 9, 14958. [CrossRef]

39. Yang, C.; Zhang, Z.; Tian, Z.; Zhang, K.; Li, J.; Lai, Y. Effects of Carboxymethyl Cellulose on the Electrochemical Characteristics and Dendrite Growth of Zinc in Alkaline Solution. J. Electrochem. Soc. 2016, 163, A1836-A1840. [CrossRef]

40. Silva, J.C.M.; Assumpção, M.H.M.T.; Hammer, P.; Neto, A.O.; Spinacé, E.V.; Baranova, E.A. Iridium-Rhodium Nanoparticles for Ammonia Oxidation: Electrochemical and Fuel Cell Studies. ChemElectroChem 2017, 4, 1101-1107. [CrossRef]

41. Yang, C.; Zhang, Z.; Tian, Z.; Lai, Y.; Zhang, K.; Li, J. Effects of various carboxymethyl celluloses on the electrochemical characteristics of zinc anode from an alkaline electrolyte. Electrochim. Acta 2017, 258, 284-290. [CrossRef]

42. Mohammadi Zardkhoshoui, A.; Hosseiny Davarani, S.S.; Hashemi, M. Fabrication of cobalt gallium oxide with zinc iron oxide on nickel foam for a high-performance asymmetric supercapacitor. New J. Chem. 2019, 43, 4590-4598. [CrossRef]

43. Pan, J.; Ji, L.; Sun, Y.; Wan, P.; Cheng, J.; Yang, Y.; Fan, M. Preliminary study of alkaline single flowing Zn-O battery. Electrochem. Commun. 2009, 11, 2191-2194. [CrossRef]

44. Masri, M.N.; Nazeri, M.F.M.; Ng, C.Y.; Mohamad, A.A. Tapioca binder for porous zinc anodes electrode in zinc-air batteries. J. King Saud Univ. Eng. Sci. 2015, 27, 217-224. [CrossRef]

45. Liu, S.; Han, W.; Cui, B.; Liu, X.; Sun, H.; Zhang, J.; Lefler, M.; Licht, S. Rechargeable Zinc Air Batteries and Highly Improved Performance through Potassium Hydroxide Addition to the Molten Carbonate Eutectic Electrolyte. J. Electrochem. Soc. 2018, 165, A149-A154. [CrossRef]

46. Ovejas, V.J.; Cuadras, A. Impedance characterization of an LCO-NMC/graphite cell: Ohmic conduction, SEI transport and charge-transfer phenomenon. Batteries 2018, 4, 43. [CrossRef]

(C) 2020 by the authors. Licensee MDPI, Basel, Switzerland. This article is an open access article distributed under the terms and conditions of the Creative Commons Attribution (CC BY) license (http://creativecommons.org/licenses/by/4.0/). 